WIDER Working Paper 2020/141

\title{
Economic complexity and structural transformation: the case of Mozambique
}

Bjørn Bo Sørensen, ${ }^{1}$ Christian Estmann, ${ }^{2}$ Enilde Francisco Sarmento, ${ }^{3}$ and John Rand ${ }^{4}$

October 2020 


\begin{abstract}
Mozambique is among the world's least complex economies. By systematically accounting for both supply- and demand-side factors, we identify new products and sectors that can help to diversify and upgrade its economy. In a supply-side analysis, we use network methods from the literature on economic complexity to identify a set of target products that are complex, require productive capabilities useful in the export of other products, and are close to Mozambique's existing productive structure. In a demand-side analysis, we use gravity models to predict the export potential of target products and markets given product-specific trade resistance and geographically dispersed demand. The broad sectoral focus of Mozambique's industrial policy is largely consistent with structural transformation and export promotion. The current prioritization of agriculture, agro-industry, and metals is especially important, while there are unexploited opportunities in machinery, vehicles, and transport equipment. We find some potential for Mozambique to export target products to neighbouring countries.
\end{abstract}

Key words: economic complexity, trade, export upgrading, structural transformation, Mozambique

JEL classification: C53, F14, O14, O25

Acknowledgements: We thank Antonio S. Cruz for valuable comments.

\footnotetext{
${ }^{1}$ Development Economics Research Group (DERG), University of Copenhagen, Copenhagen, Denmark, corresponding author: nlh494@econ.ku.dk; ${ }^{2}$ DERG; ${ }^{3}$ National Directorate of Economic Policies and Development, Ministry of Economy and Finance (MEF), Maputo, Mozambique; ${ }^{4}$ DERG

This study has been prepared within the project on Inclusive growth in Mozambique-scaling-up research and capacity implemented in collaboration between UNU-WIDER, University of Copenhagen, University Eduardo Mondlane, and the Mozambican Ministry of Economics and Finance. The project is financed through specific programme contributions by the governments of Denmark, Finland, and Norway.
}

Copyright (C) UNU-WIDER 2020

Information and requests: publications@wider.unu.edu

ISSN 1798-7237 ISBN 978-92-9256-898-6

https://doi.org/10.35188/UNU-WIDER/2020/898-6

Typescript prepared by Luke Finley.

United Nations University World Institute for Development Economics Research provides economic analysis and policy advice with the aim of promoting sustainable and equitable development. The Institute began operations in 1985 in Helsinki, Finland, as the first research and training centre of the United Nations University. Today it is a unique blend of think tank, research institute, and UN agency — providing a range of services from policy advice to governments as well as freely available original research.

The Institute is funded through income from an endowment fund with additional contributions to its work programme from Finland, Sweden, and the United Kingdom as well as earmarked contributions for specific projects from a variety of donors.

Katajanokanlaituri 6 B, 00160 Helsinki, Finland

The views expressed in this paper are those of the author(s), and do not necessarily reflect the views of the Institute or the United Nations University, nor the programme/project donors. 
Since its independence from Portugal in 1975, Mozambique has undergone several remarkable transformations. In the mid-1980s it transitioned from a planned to an open economy. The country achieved peace from a devastating war in 1992, and it introduced multi-party democracy in 1994. In the wake of these progressions, the Mozambican economy has grown at an impressive average annual rate of around 7.5 per cent (1999 to 2015). The rapid growth in recent decades was partly a consequence of starting from a very low base: 44.4 per cent of Mozambique's GDP per capita was destroyed between 1975 and 1986 as a consequence of the war (Cruz et al. 2018). It was, however, also aided by the implementation of credible macroeconomic policies; high inflows of foreign aid and foreign direct investments (FDI); investments in health, education, and infrastructure; institutional reforms; a favourable external environment; and good weather conditions (Arndt et al. 2000; Cruz and Mafambissa 2016). In addition, a booming extractives sector and the Mozal aluminium smelter mega-project have driven strong export growth. In 2015, however, Mozambique entered a macroeconomic crisis, with a sharp decline in economic growth rates and an explosion of public debt, which has risen from 40 to 130 per cent of GDP since 2012 (Cruz et al. 2018; Dietsche and Esteves 2018).

In this paper, we argue that in order to achieve sustained economic growth in the future Mozambique needs to invest in the productive capabilities necessary for the country to diversify and upgrade its economy and export structure. The argument draws on economic complexity theory, stating that economic growth occurs as countries accumulate productive capabilities that enable them to produce and export a diverse set of complex products. Supporting the theory, empirical evidence shows that a country's diversification in sophisticated export products is a strong predictor of economic growth (Hausmann et al. 2013; Hidalgo and Hausmann 2009). The theory implies that economic growth follows a structural transformation process whereby productive resources are moved from low- to high-complexity activities.

Nowhere is the quest to improve economic complexity more important than in Mozambique. The country remain one of the world's least complex economies despite the impressive growth rates of recent decades. That is, the majority of Mozambique's growth cannot be attributed to structural change. For instance, Jones and Tarp (2015) find that recent aggregate growth has been driven by productivity growth within the capital-intensive mining sector and by employment growth in lowproductivity service activities. Overall, though, labour reallocation has played only a modest role in Mozambique's post-conflict productivity growth, and the majority of its labour force continues to rely on low-productivity agricultural activities. We argue that to improve the prospect of sustained economic growth over the long term, industrial policy should ignite structural transformation, not replicate previous decades' focus on attracting large-scale international investments into the extractive industries.

Recent government policies do acknowledge the need to move away from a reliance on primary commodity sectors and diversify export products and markets. Both manufacturing and tourism are recognized as priority sectors in the National Development Strategy (2015-2035), along with agriculture, fishery, and the extractives sector (GoM 2014a). The Industrial Policy and Strategy (2016-2025) has the objective to 'make industry the main vehicle for achieving prosperity and well-being'. It outlines seven priority sectors to achieve this goal: (i) food and agro-industry; (ii) clothing, textiles, and footwear; (iii) non-metallic minerals; (iv) metallurgy and manufacture of metal products; (v) wood and furniture processing; (vi) chemistry, rubber, and plastics; and (vii) paper and printing. These priority sectors are selected based on national priority, contribution to the current production level, the origin of raw materials used in production, job creation, import 
substitution, export potential, potential to generate upstream and downstream linkages, and ease of policy implementation (GoM 2014b).

In this paper, we identify an alternative set of new products and sectors that could be targeted by industrial policy with the explicit aim of diversifying and upgrading Mozambique's economy and boosting its export revenue. First, we take a supply-side perspective and use network methods from the literature on economic complexity to identify products that are complex, require productive capabilities useful in the export of other products, and are close to Mozambique's existing productive structure. We find that Mozambique's industrial policy is broadly in line with a structural transformation agenda-especially the priority given to agriculture, agro-industry, and metal products. However, the sector identified as holding the largest potential for Mozambiquemachinery and electronics - is not currently prioritized in the Industrial Policy and Strategy (20162025). Products in this sector are complex and well connected, and Mozambique is already exporting some of them, although without a revealed comparative advantage (RCA). Instruments ${ }^{1}$ and vehicles and transport equipment constitute two other product sectors identified as holding an unaddressed potential.

Second, we use gravity equations to account for demand-side factors by modelling which export markets and products are most feasible for Mozambique to target given product-specific trade resistance and geographically dispersed demand. The results indicate synergies between the structural transformation potential of different sectors and their export potential. For current priority sectors, demand conditions for target products are particularly favourable in agriculture and agro-industry, metals, and minerals. We also find the export potential to be very high in machinery and electronics and vehicles and transport equipment, underlining the need for industrial policy to consider their inclusion as priority sectors. In terms of export markets, we estimate that Mozambique's largest current trade partners are generally those with the highest potential to import its target products. The pay-off from export market diversification is thus limited. Yet we do find potential for Mozambique in exporting to its neighbours and other Southern African countries. Exploiting and expanding the free trade agreement under the South African Development Community (SADC) seem important for Mozambique to realize this potential, which deviates somewhat from the country's current trade strategies.

The paper draws on theoretical ideas from the literature on economic complexity, methodological approaches from empirical work on international trade (gravity models) and economic complexity (network science), and empirical results from previous literature attempting to identify key sectors in Mozambique's structural transformation process. We contribute directly to the latter two dimensions of the literature, but discuss all three in turn below.

Theoretically, our core argument relies on two seminal ideas developed in the literature on economic complexity. First, the wealth of nations is a function of the set of productive capabilities that countries possess and are able to combine for productive purposes. One can think of 'capabilities' as an umbrella-term capturing everything from the factors of production (labour and capital) to institutional quality and productive knowledge. Countries with more productive capabilities are able to produce many sophisticated goods and tend to have a higher level of income (Hidalgo and Hausmann 2009). Second, this implies that countries diversify into new economic activities, undergo structural transformation, and grow when they acquire and combine capabilities in new ways (Hausmann and Klinger 2007; Hidalgo et al. 2007). This process of structural transformation

\footnotetext{
${ }^{1}$ Identified instruments include (i) other parts for machines and appliances; (ii) machines for testing the mechanical properties of materials; (iii) musical instruments, wind; and (iv) instruments designed for demonstrational purposes (see Appendix Tables A1-A4).
} 
is an incremental, path-dependent process due to two simple characteristics of productive capabilities. One, many capabilities are product-specific due to phenomena such as asset specificity and tacit knowledge. Two, the capabilities employed in the production of different goods are complementary to varying degrees. It is thus less costly for countries to undertake 'related diversification', gradually moving into economic activities similar to those that they already know how to undertake. Besides path dependency, the nature of productive capabilities also explains why the structural transformation process may entail hiccups for developing countries that only know how to produce goods, whose capabilities do not complement other activities (Hausmann and Klinger 2007; Hidalgo et al. 2007).

Methodologically, we propose a new method to rank the attractiveness of products and export destinations by combining the supply-side-focused complexity analysis with a structured demandside analysis based on gravity models, ranking these products' revenue-generating trade potential. In combination, the two analyses constitute a coherent methodological framework that considers (i) both demand- and supply-side factors, (ii) the importance of diversification (extensive margin) and the export potential of new industries (intensive margin), and (iii) the need for long-term structural transformation as well as the pressing issue of export revenue generation.

Our supply-side analysis follows the methodology employed in a number of studies taking the ideas in economic complexity as a starting point to guide industrial policies in developed and developing countries alike. Examples include policy reports on the Netherlands (Hausmann and Hidalgo 2013), South Africa (Hausmann and Klinger 2006a), Rwanda (Hausmann and Chauvin 2015), Jordan (Hausmann et al. 2019), Panama (Hausmann et al. 2016, 2017), Myanmar (Ayres and Freire 2014), Uganda (Hausmann et al. 2014), and Southern Africa (Hidalgo 2011). The main objective in these studies is clear: in order to achieve economic growth, countries need to diversify and upgrade their productive structure by acquiring new capabilities. While it is impossible to identify which exact capabilities are most important, it is possible to attach sets of capabilities to products and then target the products that rely on the most feasible set of capabilities. Specifically, industrial policy should ideally target products that force countries to acquire new and sophisticated capabilities (complex products) and products that ease further diversification by relying on capabilities that are useful in many different production processes. Importantly, however, industrial policy should simultaneously take into account what countries already know how to do well in order to maximize the efficiency of the structural transformation process.

The economic complexity methodology and hence most of the empirical studies mentioned above are silent on the question of which products (and destinations) hold the highest potential to generate export revenue. This is a non-trivial shortcoming, especially for countries like Mozambique, whose trade deficit and low GDP per capita force government policies to favour interventions with a not-too-distant pay-off. Evidently, addressing these issues is an important objective in the Industrial Policy and Strategy 2016-2025, which includes export potential and import substitution as two core criteria in the selection of priority industries. We take a demandside perspective to address this shortcoming, using gravity models from the international trade literature to map the export potential of products (and markets) in Mozambique. For instance, our estimates of a product's export potential are a function of importer capacities in all countries other than Mozambique (such as country-product-specific demand and competition) and the accessibility of those import destinations to Mozambique (given by factors such as distance). The approach is closely related to work in the economic geography and trade literature that uses equations from trade models to measure 'total demand exposure' in a location as a function of the demand and accessibility of other locations (see for example Hanson 2005; Head and Mayer 2004; Redding and Venables 2004). In contrast to these studies that measure the total demand exposure across locations, we are only interested in the total demand exposure in Mozambique. Therefore, 
we let our estimates vary across products and attempt to single out the products and destinations with the highest export potential for Mozambique.

Empirically, the key products and sectors identified in this paper complement the results from previous studies aiming to identify important sectors in Mozambique's structural transformation process. Two sectors have gained particular attention in the literature. First, the benefits of developing the agricultural and agro-processing sectors have been analysed in a series of computable general equilibrium (CGE) studies. Jensen and Tarp (2004) estimate that simultaneous productivity improvements in Mozambique's agricultural sector and agro-industry sectors (food processing and textiles) will lead to significant economic expansion, noting strong synergies in what they call an agricultural-development-led-industrialization strategy. ${ }^{2}$ Other studies use dynamic CGE simulations to show that large-scale investment in the development of a biofuel sector in Mozambique has the potential to foster economic growth, increase employment, and reduce poverty (Arndt et al. 2010; Hartley et al. 2019). In general, these models corroborate our finding that investment in capabilities conducive to agriculture and agro-processing constitutes a potentially important industrial strategy for Mozambique.

Second, the extractives sector in Mozambique has received much scholarly as political attention in recent years-especially since the discoveries of giant natural gas deposits in the Rovuma Basin since 2009. The net present value of the deposits has been estimated to be many times larger than Mozambique's current GDP (Toews and Vezina 2018), and their exploitation has the potential to strengthen economic growth and fiscal revenues. An International Monetary Fund report even predicted that the new discoveries alone could boost the country's average real GDP growth rate to 24 per cent between 2021 and 2024 (IMF 2016). Besides this direct effect, the impact on other sectors of investment surges in the extractives sector has been examined in several studies. Toews and Vezina (2018) show that the gas discoveries have generated an FDI bonanza in non-extractive industries, potentially facilitating economic diversification. Dietsche and Esteves (2018) and Roe (2018) draw, respectively, on Mozambique's current policies and experiences from other developing countries to appraise the prospects of economic diversification fuelled by extractive industries through backward and forward linkages to the rest of the economy. Their conclusions vary from scepticism to cautious optimism. The analysis in this paper lends support to a sceptic position: we find high export potential for minerals, but we do not identify the extractives industry as an important driver in Mozambique's structural transformation process because it generally produces unsophisticated products that do not rely on capabilities complementary to those in other sectors. ${ }^{3}$ Instead, the analysis in this paper identifies machinery and electronics as a key industry for Mozambique. Machinery products are complex, rely on many widely useful capabilities, and have high export potential in Mozambique. In addition, Mozambique already has some exports in the sector, hinting at the viability of the sector. This finding constitutes a significant contribution, as machinery does not feature on the list of priority sectors in the country's Industrial Policy and Strategy 2016-2025.

The rest of the paper is organized in three sections. Section 2 lays forth the supply-side analysis. Here, we first describe the data and methodology, before we identify target products that are

\footnotetext{
${ }^{2}$ A recent study by Mondlane and van Seventer (2019) also finds the food-processing sector to be attractive from a distributional point of view. Based on a social accounting matrix (SAM) multiplier model, they find that an exogenous expansion of the sector has strong potential to raise income in poor rural households.

${ }^{3}$ That is not to say that we dismiss the significance of the extractives sector or deny its potential to boost fiscal revenues and growth over the coming decades. Rather, we argue that the enclave characteristic of the sector means that its take-off is unlikely to drive structural transformation. Industrial policy targeting the sector for its transformative power is likely misguided.
} 
feasible for Mozambique to move into as part of its structural transformation process. The demand-side analysis is presented in the third section. We first describe the data and methodology applied to run gravity models, before we use these models to rank Mozambique's target products in accordance with their export potential. In the final section, we discuss and conclude on our findings.

\section{$2 \quad$ Supply-side analysis}

\subsection{Data}

The supply-side analysis is built on country-product-level world trade data from the United Nations Statistical Division (COMTRADE) and cleaned by the Growth Lab at Harvard University using the Bustos-Yildrim Method (Growth Lab 2019). The method exploits the fact that trade flows are reported twice (once by exporters, once by importers) to correct for inconsistencies in reporting while taking into account the reliability of each country's trade records. After dropping observations on services and products not specified according to kind, the dataset covers 242 countries and 1,241 products from 1995 to 2018 using four-digit product codes from the 1992 revision of the United Nations Harmonized System (HS). We undertake an additional cleaning process in order to reduce noise in the data. First, we drop all products with global exports of less than US $\$ 10$ million on average from 2015 to 2018. Second, we exclude countries exporting less than US $\$ 1$ billion on average over the same time span. We further use population data from the World Development Indicators (World Bank 2020) to drop all small countries with less than 1.25 million inhabitants in 2018 (including countries with no population data). ${ }^{4}$ Fourth, we drop Chad, Iraq, and Macau due to questions on unreliable trade data (Hausmann et al. 2013). Finally, we keep only countries with trade data in all years. Our final sample covers 131 countries and 1,221 products.

\subsection{Methodology: economic complexity}

\section{Measuring the complexity of countries and products}

Quantifying something as fuzzy as the set of capabilities that different countries hold, and the capabilities it take to produce and export different products, is naturally a tricky exercise. While the exact method applied in the literature varies (see Hidalgo and Hausmann 2009 and Tacchella et al. 2012 for two prominent examples), all of the methods used build on the same intuition. Countries are connected to products via capabilities in a tripartite network as shown in Figure 1. While it is impossible to observe these capabilities directly, it is possible to infer the amount of complementary capabilities layered in countries and products through a bipartite network linking countries to the products they are able to export. Saltarelli et al. (2020) find that countries' export patterns mirror their domestic production structures in manufacturing and sectors producing physical goods. This indicates that countries' exports serve as reasonable approximations not only of their export capabilities but also of their productive capabilities (economic complexity) in general. Countries able to export many products can be assumed to possess a larger set of complementary capabilities. A first approximation of countries' complexity is therefore their export diversity. On the other hand, products exported by only a few countries are likely to require many hard-to-

\footnotetext{
${ }^{4}$ Applying a population threshold of between 1.2 and 1.25 million is standard in the literature (see for example Albeaik et al. 2017; Hausmann et al. 2013).
} 
acquire capabilities. The ubiquity of products (i.e. the number of countries able to export them) can therefore be assumed to be inversely correlated with their complexity.

Figure 1: The hidden capabilities layer

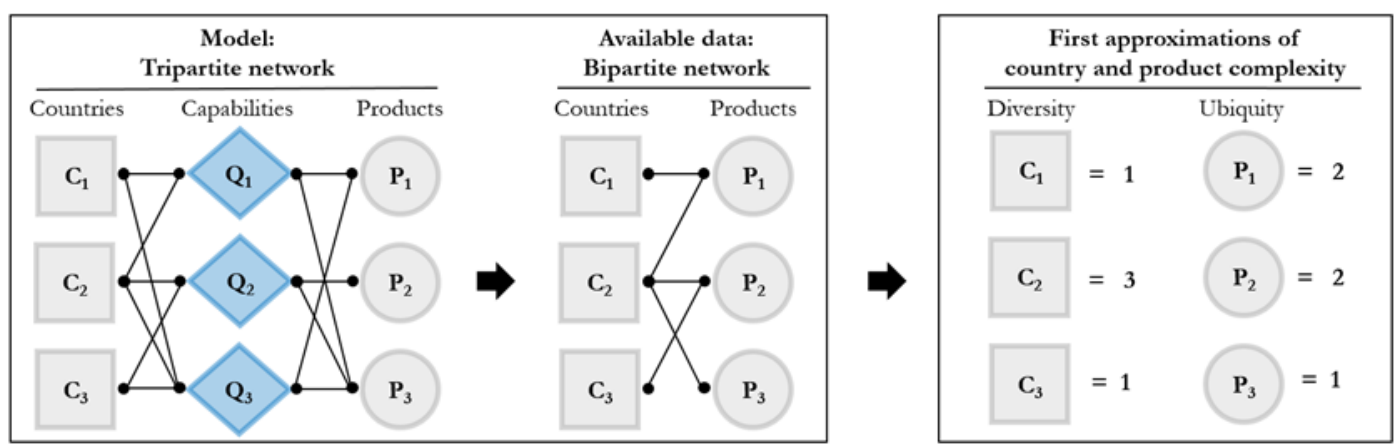

Source: reproduced from Sørensen (2020: 14), originally based on Cristelli et al. (2013).

We follow the approach in Hausmann et al. (2013) and construct the country-product adjacency matrix $M$ from international trade data. Each row represents a country $c$ and each column a product $p$. We define a country as being linked to a product if it exports that product competitively. Formally, each element in the adjacency matrix, $M_{c p}$, takes the value of 1 if $c$ has a revealed comparative advantage $(\mathrm{RCA}>1)$ in exporting $p$, at time $t$ or on average over the past four years, and 0 otherwise:

$$
M_{c p}=\left\{\begin{array}{c}
1 \text { if } R C A_{c p}^{t}>1 \text { or }\left(\frac{1}{4} \sum_{i=0}^{4} R C A_{c p}^{t-i}\right)>1 \\
0 \text { otherwise }
\end{array}\right.
$$

where

$$
R C A_{c p}^{t}=\frac{X_{c p}^{t}}{\sum_{c} X_{c p}^{t}} / \frac{\sum_{p} X_{c p}^{t}}{\sum_{c, p} X_{c p}^{t}}
$$

and $X_{c p}^{t}$ is country c's total export of product $p$ at time $t$. When calculating $R C A_{c p}^{t}$, we follow the standard set by Hausmann et al. (2013) and average the denominator over three years. Yet we also smooth the entire $R C A_{c p}^{t}$ over four years when populating the adjacency matrix-equivalent to the length of the average business cycle in many developing countries (Rand and Tarp 2002) - to avoid a scenario where it drops below the threshold of 1 in a given year due to world price fluctuations, exchange rate volatility, or business cycles. Going forward, we drop the time-period subscripts to avoid notational clutter, but the variables remain time dependent.

From $M$ we can formally derive the diversity of countries and the ubiquity of products in each time period:

$$
\begin{aligned}
& \text { Diversity }=k_{c, 0}=\sum_{p} M_{c p} \\
& \text { Ubiquity }=k_{p, 0}=\sum_{c} M_{c p}
\end{aligned}
$$


Ubiquity and diversity are, of course, imperfect approximations of product and country complexity. Take diamonds as an example. Only a few countries are able to export them, but they are not especially difficult to mine and they are often exported by countries (such as Botswana) that do not export many other goods. To account for these inconsistencies, it is possible to correct our initial proxy for the complexity of diamonds by accounting for the diversity of the countries producing diamonds. Similarly, we can correct our initial country complexity measure by accounting for the ubiquity of the products that a country is able to produce. Put differently, it is possible to use one of the above equations to correct the other through an algorithm that jointly and iteratively calculates the average value of the measures obtained in the previous iteration of the algorithm. This approach is called the Method of Reflections (Hidalgo and Hausmann 2009) and can by mathematically formulated as:

$$
\begin{aligned}
& k_{c, N}=\frac{1}{k_{c, 0}} \sum_{p} M_{c p} k_{p, N-1} \\
& k_{p, N}=\frac{1}{k_{p, 0}} \sum_{c} M_{c p} k_{c, N-1}
\end{aligned}
$$

where $k_{c, N}$ and $k_{p, N}$ are country and product complexity after $N$ iterations of the algorithm. Inserting Equation 6 into 5:

$$
\begin{gathered}
k_{c, N}=\frac{1}{k_{c, 0}} \sum_{p} M_{c p} \frac{1}{k_{p, 0}} \sum_{c^{\prime}} M_{c^{\prime} p} k_{c^{\prime}, N-2} \\
k_{c, N}=\sum_{c^{\prime}} k_{c^{\prime}, N-2} \sum_{p} \frac{M_{c \prime p} M_{c p}}{k_{c, 0} k_{p, 0}} \\
k_{c, N}=\sum_{c^{\prime}} k_{c^{\prime}, N-2} \widetilde{M}_{c, c^{\prime}}^{C}
\end{gathered}
$$

where

$$
\widetilde{M}_{c, c^{\prime}}^{C}=\sum_{p} \frac{M_{c^{\prime} p} M_{c p}}{K_{c, 0} K_{p, 0}}
$$

Notice that the solution to Equation 7 can be formulated as an eigenvector problem. We first write Equation 7 in vector notation:

$$
\overrightarrow{\mathbf{k}}_{\mathrm{N}}=\widetilde{\mathbf{M}}^{\mathrm{C}} \times \overrightarrow{\mathbf{k}}_{\mathrm{N}-2}
$$

where $\overrightarrow{\mathbf{k}}_{\mathrm{N}}$ is a vector whose $c$ th element is given by $k_{c, N}$ and $\widetilde{\mathbf{M}}^{\mathrm{C}}$ is a matrix with the $\left(c, c^{\prime}\right)$ th element given by $\widetilde{M}_{c, c^{\prime}}^{C}$. Taking $N$ to infinity (equivalent to running an algorithm for $\infty$ iterations), there is a perfect rank correlation between $\overrightarrow{\mathbf{k}}_{\mathrm{N}}$ and $\overrightarrow{\mathbf{k}}_{\mathrm{N}-2}$. In other words, $\overrightarrow{\mathbf{k}}$ remains fixed up to a scalar factor, $\lambda$ : 


$$
\widetilde{\mathbf{M}}^{\mathrm{C}} \times \overrightarrow{\mathbf{k}}=\lambda \overrightarrow{\mathbf{k}}
$$

It follows that $\overrightarrow{\mathbf{k}}$ is the eigenvector of $\widetilde{\mathbf{M}}^{\mathrm{C}}$ and $\lambda$ is the corresponding eigenvalue. The eigenvector capturing the largest variance in the system is the one associated with the second-largest eigenvalue (the eigenvector associated with the largest eigenvalue is just a vector of ones). This vector is defined as the Economic Complexity Index (ECI) for countries (Hausmann et al. 2013). We use the ECI to obtain the Product Complexity Index (PCI) by substituting ECI for $k_{c, N-1}$ in Equation $6 .{ }^{5}$

\section{Measuring the relatedness of, and distance to, products}

To construct a measure of the degree to which products hold complementary capabilities, we construct the 'product space' network following Hidalgo et al. (2007). In this network, each node represents a product and each weighted link measures the proximity between two products - that is, the extent to which they rely on similar capabilities. Proximities are calculated based on the simple idea that if many countries exporting one product are simultaneously able to export another, these two products must rely on many complementary capabilities. Technically, we estimate the proximity $\varphi$ between product $p$ and $p^{\prime}$ as the minimum of the pairwise probabilities that a country $c$ exports one of the products with an RCA above 1, given that it also exports the other with an RCA above 1:

$$
\varphi_{p, p^{\prime}}=\min \left\{P\left(M_{c, p}=1 \mid M_{c, p^{\prime}}=1\right), P\left(M_{c, p^{\prime}}=1 \mid M_{c, p}=1\right)\right\}
$$

which is equivalent to

$$
\varphi_{p, p}=\frac{\sum_{c} M_{c, p} M_{c, p^{\prime}}}{\max \left(k_{p, 0} k_{p^{\prime}, 0}\right)}
$$

where $M$ is the matrix described above and $k_{p, 0}$ is the ubiquity of product $p$ as defined in Equation 4.

To capture the 'capability gap' between a particular product $p$ and a country $c$ 's current productive knowledge, we calculate a measure of distance, $d_{c, p}$, to product $p$. This is the sum of proximities between $p$ and all the products that country $c$ is currently not making, normalized by the sum of proximities between product $p$ and all other products:

$$
d_{c, p}=\frac{\sum_{c}\left(1-M_{c, p^{\prime}}\right) \varphi_{p, p^{\prime}}}{\sum_{p^{\prime}} \varphi_{p, p^{\prime}}}
$$

\section{Measuring opportunities for further diversification}

Since export diversification and upgrading is a path-dependent process, it is important to quantify whether Mozambique is well positioned in the product space, allowing it to easily jump into new and complex products. To do so, we construct the Complexity Outlook Index (COI) for country c, following Hausmann et al. (2013):

\footnotetext{
5 This is equivalent to repeating the procedure above, plugging Equation 5 into 6, and obtaining the eigenvector associated with the second-largest eigenvalue.
} 


$$
\operatorname{COI}_{c}=\sum_{p}\left(1-d_{c, p}\right)\left(1-M_{c, p}\right) P C I_{p}
$$

where $d_{c, p}$ is the distance for country $c$ to product $p, M$ is the country-product matrix, and $P C I$ is the Product Complexity Index defined above. COI measures how close a country's current capabilities lie to not-yet-produced products, weighted by the complexity of those products. A high COI means that a country is well positioned to diversify into new and complex export products.

It is also possible to calculate how much a particular not-yet-produced product $p$ would add to country $c$ 's diversification options. The Opportunity Gain Index (OGI) measures how much the COI would change for country $c$ if it were to acquire the capabilities necessary to export product $p$ competitively. Formally, we define OGI as:

$$
O G I_{c, p}=\sum_{p^{\prime}} \frac{\varphi_{p, p^{\prime}}}{\sum_{p^{\prime \prime}} \varphi_{p^{\prime}, p^{\prime \prime}}}\left(1-M_{c, p^{\prime}}\right) P C I_{p^{\prime}}
$$

\subsection{A history of economic complexity in Mozambique}

In this section, we draw on the variables and networks presented above to provide a brief overview of Mozambique's past and present export structure and economic complexity, and we subsequently discuss the country's potential for future diversification.

Since the peace deal in 1992 and the turn to multi-party democracy in 1994, Mozambique has experienced impressive economic growth. Yet this growth has not been followed by structural change. The country's export dynamics over the past decades pay testimony to this structural deadlock. On one hand, Mozambique has seen strong growth in export volumes. This has primarily been driven by exports of unwrought aluminium from the Mozal aluminium smelter at the turn of the millennium and the gradual take-off of the country's fossil fuels exports. These shifts are clearly visible in Figure 2a, showing the split between the country's exports in primary product sectors from 1998 to 2018. The product sector contributing most to export revenues has changed from agriculture (mainly crustaceans, cashew nuts, and wood), through metals (almost exclusively unwrought aluminium), and finally to minerals (primarily fossil fuels such as petroleum oil and gases, coke, and coal). On the other hand, Mozambique's portfolio of exported products has not changed substantially from an economic complexity point of view. The combined share in total exports of low-complexity natural resources and primary commodities has remained high and constant over time (approximately 90 per cent). It is not just that Mozambique's export basket is, and has been, unsophisticated. It is also undiversified. In 2004, unwrought aluminium accounted for more than 65 per cent of total exports. In 2018, almost 75 per cent of the country's exports came from just ten products (see Figure $2 \mathrm{~b}$ ). These products all have PCI scores at or below average (zero) and do not substantially add to the complexity of the Mozambican economy as a whole. Thus, industrial policies focusing on the intensive margin of trade-that is, boosting the export volume of these marque products—-may increase Mozambique's export revenues, but they will not increase the country's economic complexity. 
Time trend
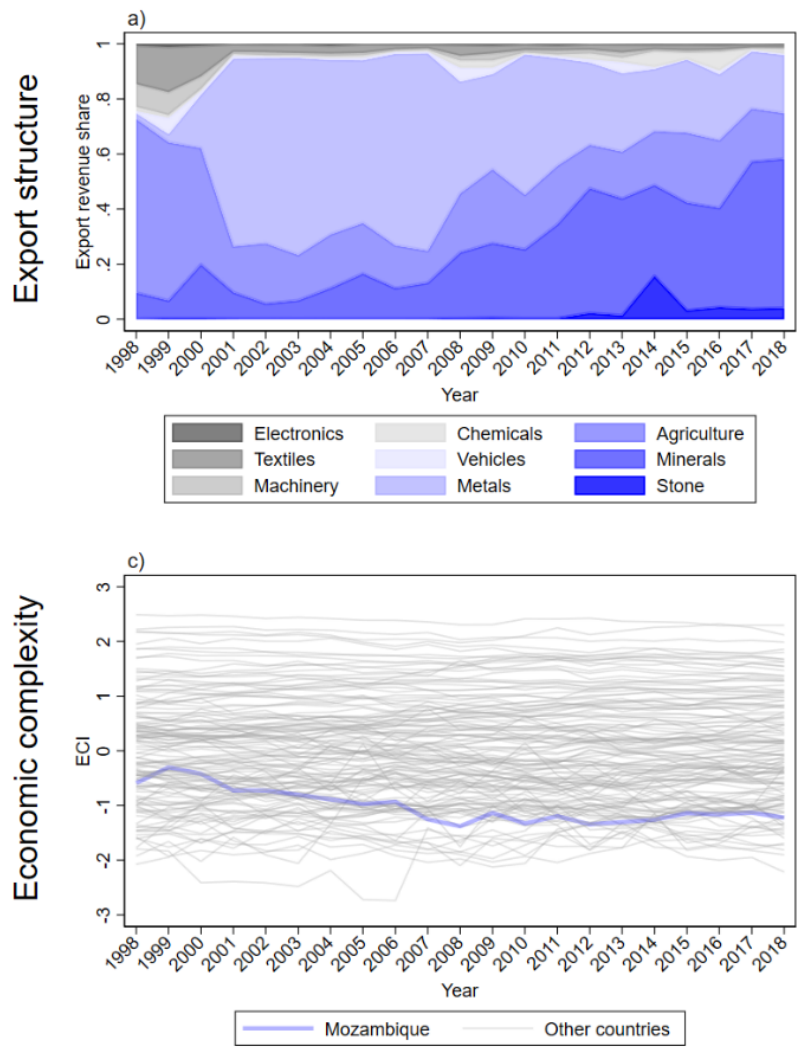

Current pattern (2018)
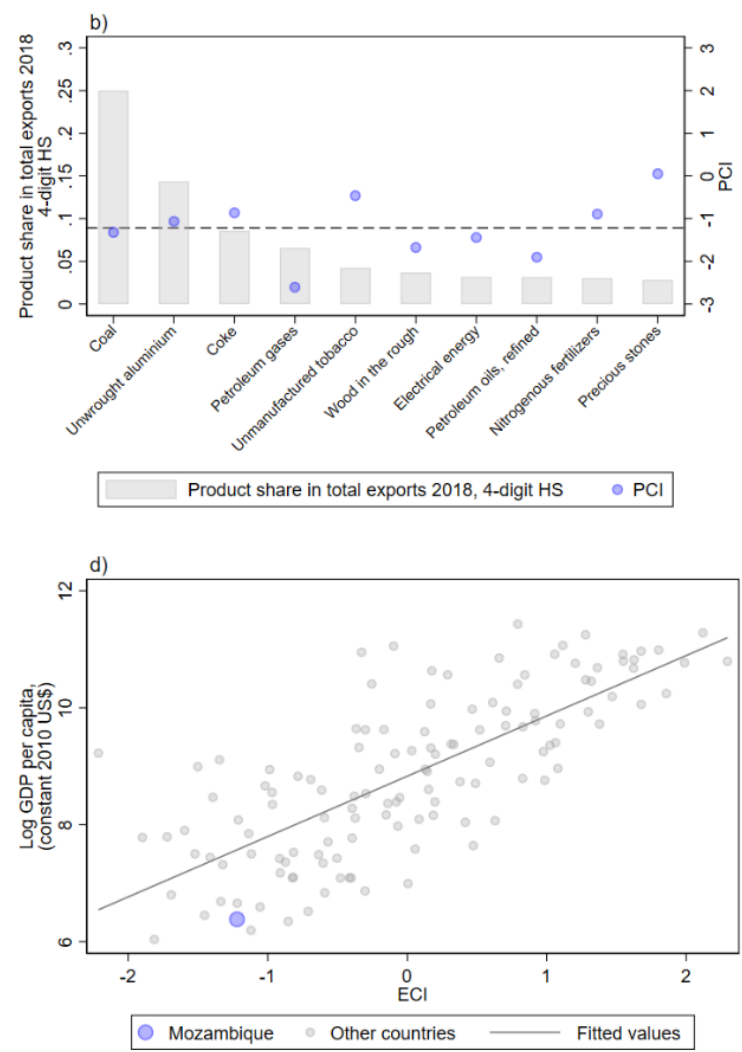

Note: (a) shows different product groups' share in Mozambique's export revenue over time; products are grouped in accordance with the approach outlined in Harvard's online Atlas of Economic Complexity (Atlas 2019); product group 'Other' is left out of the figure; each product group's share is calculated based on the total export volume of included products. (b) Bars indicate the share in export revenue of Mozambique's ten largest export products in 2018 defined at the four-digit HS level; dashed line indicates Mozambique's economic complexity in 2018; dots show the PCl scores of each of these products; dots above the dashed line contribute positively to raising Mozambique's economic complexity. (c) Shows the $\mathrm{ECl}$ of countries over time. (d) Illustrates the positive relationship between the log of GDP and $\mathrm{ECl}$.

Source: authors' calculations based on trade data from Growth Lab (2019) and World Development Indicators (World Bank 2020).

The trends described above signal that Mozambique has been unable to acquire the new productive capabilities necessary to diversify and upgrade its export basket. As a consequence, the country has remained one of the world's least complex economies for the past 20 years (see Figure 2c). In fact, its position in the ECI has worsened since 1998, dropping from 93rd to 117th place out of $131 .{ }^{6}$ This has clear consequences for economic development. Figure $2 \mathrm{~d}$ plots the positive relationship between GDP per capita and ECI. Complex countries enjoy a higher standard of living. Although Mozambique ranks among the worst performers on both scales, the graph also paint an optimistic picture of the future growth potential of the country. In short, ECI has been shown to be a key determinant of economic growth, as countries tend to converge towards the values predicted by the simple linear fit shown in the figure (Hausmann et al. 2013). That is, the residuals hold information about countries' future growth rates. Countries located under the regression line-like Mozambique-have a lower level of GDP per capita than what could be

\footnotetext{
${ }^{6}$ Authors' own calculations based on based on trade data from Growth Lab (2019).
} 
expected given their current capabilities. On average, it is projected that these countries will enjoy higher future growth rates than will the countries above the regression line (Hausmann et al. 2013). On one hand, this indicates that Mozambique may enjoy high growth rates in the coming years. On the other hand, it also implies that the country will be even better set up for growth if it is able to increase its economic complexity further.

Given the current structure of Mozambique's economy, how is the country positioned to diversify, upgrade, and increase its level of economic complexity? Figure 3a shows that Mozambique's exports are located in the outskirts of the product space (only products where Mozambique has a RCA $>1$ are coloured). Thus, the products Mozambique currently knows how to export require very few capabilities that are useful in exporting other products. Consequently, it will be very difficult for Mozambique to learn to export many new and sophisticated products, suggesting that its road to a complex economy is challenging. This idea can be formally measured through the COI (Equation 12), indicating the extent to which countries are located close to new products, weighted by the complexity of those products. Figure 3b shows the relationship between countries' COI and ECI. It is clear that Mozambique is poorly positioned to diversify into complex products when compared with other countries. That said, the inverted U-shaped relationship between COI and ECI indicates that the opportunities for diversification tend to increase as low-complexity economies acquire more and more productive capabilities. In other words, it is potentially very rewarding to accept the initial cost necessary to acquire new capabilities to produce new products, because this lowers the cost of future diversification.

Figure 3: Mozambique's opportunities for structural transformation (2018)

a)

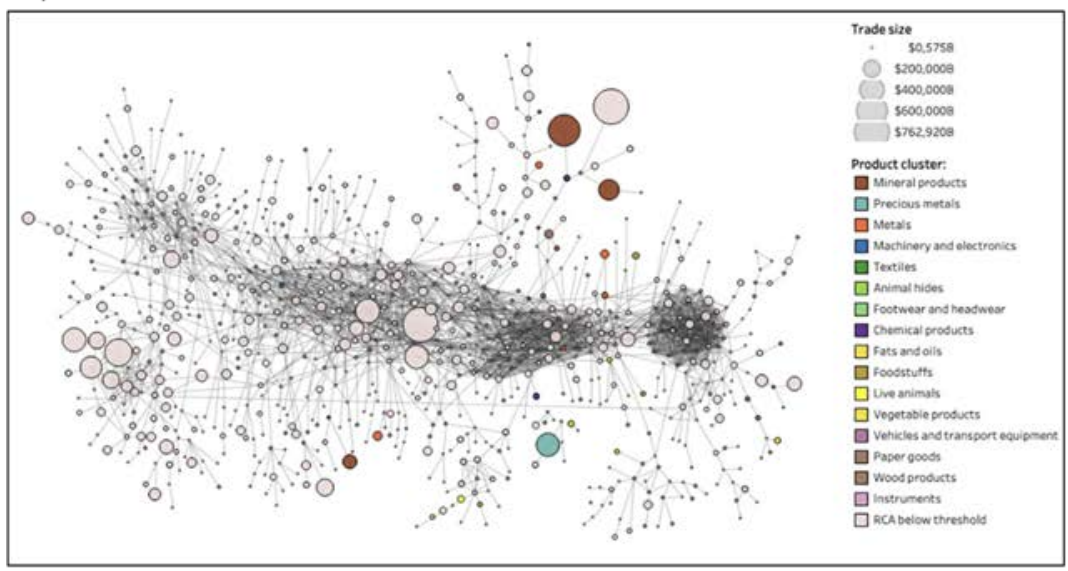

Mozambique in the Product Space b)

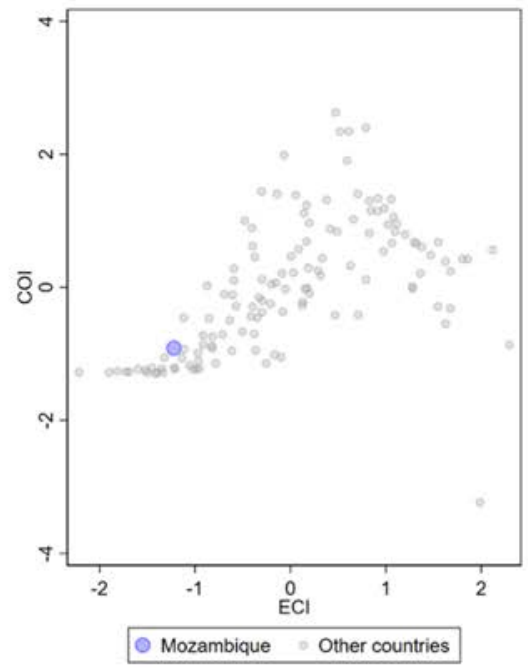

Note: in (a), each node represents a product at the HS four-digit level (rev. 92); nodes are connected based on the similarity of the capabilities it takes to export them; each node is sized in proportion to world trade in that product; pale pink nodes represent products that Mozambique did not export with an RCA > 1 in 2018; other coloured nodes represent products that Mozambique did export with an RCA > 1 in 2018.

Source: (a) data points for network skeleton from Growth Lab (2019), populated with authors' RCA calculations as detailed in Equations 1 and 2; (b) authors' own calculations based on trade data from Growth Lab (2019).

\subsection{Selecting target products}

In order to increase Mozambique's economic complexity, industrial policies should ideally support the production of highly complex products (high PCI) and products that rely on capabilities used in many other products, thereby opening up paths $t$ future diversification (high OGI). Unfortunately for Mozambique, products with these characteristics tend to lie further away from 
its current productive knowledge (measured by distance, $d_{c, p}$, from Equation 11). Figure 4 visualizes the trade-off between PCI/OGI and distance. Each dot in the figure represents one of the 1,111 products that Mozambique did not produce with a RCA > 1 in 2018.

Figure 4: Mozambique's trade-off between (a) $\mathrm{PCl}$ and distance and (b) OGI and distance
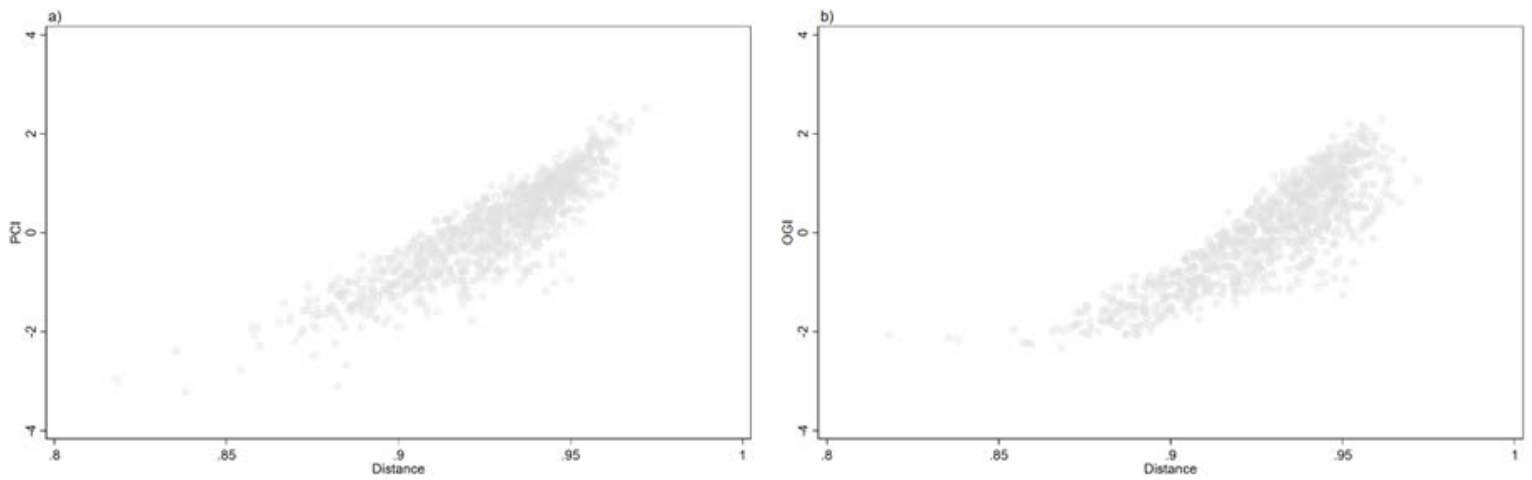

Source: authors' calculations based on trade data from Growth Lab (2019).

In the following, we identify a broad set of 'feasible products' given the criteria mentioned above. We also discuss how to narrow down the set of feasible products to a set of 'target products' using weights.

\section{Feasible products}

To identify feasible products, we apply a two-step filter to discard some of the 1,111 products depicted in Figure 4. Our approach and the final set of feasible products are depicted visually in Figure 5. First, we remove all products with a complexity score lower than Mozambique's level of complexity. These products rely on unsophisticated capabilities that will not help Mozambique upgrade its productive structure. Second, we follow the approach in Hausmann and Chauvin (2015) and remove products with very high-distance scores. These products are so detached from Mozambique's current productive knowledge that it would be very difficult and costly to attain the full set of capabilities needed for their production. Specifically, we remove all products beyond the 75th percentile (this is a judgement call, as no clear cut-off exists). We define Mozambique's feasible products as those that are highlighted in both Figure $5 \mathrm{a}$ and $5 \mathrm{~b}$.

Figure 5: Identifying the set of feasible products for Mozambique
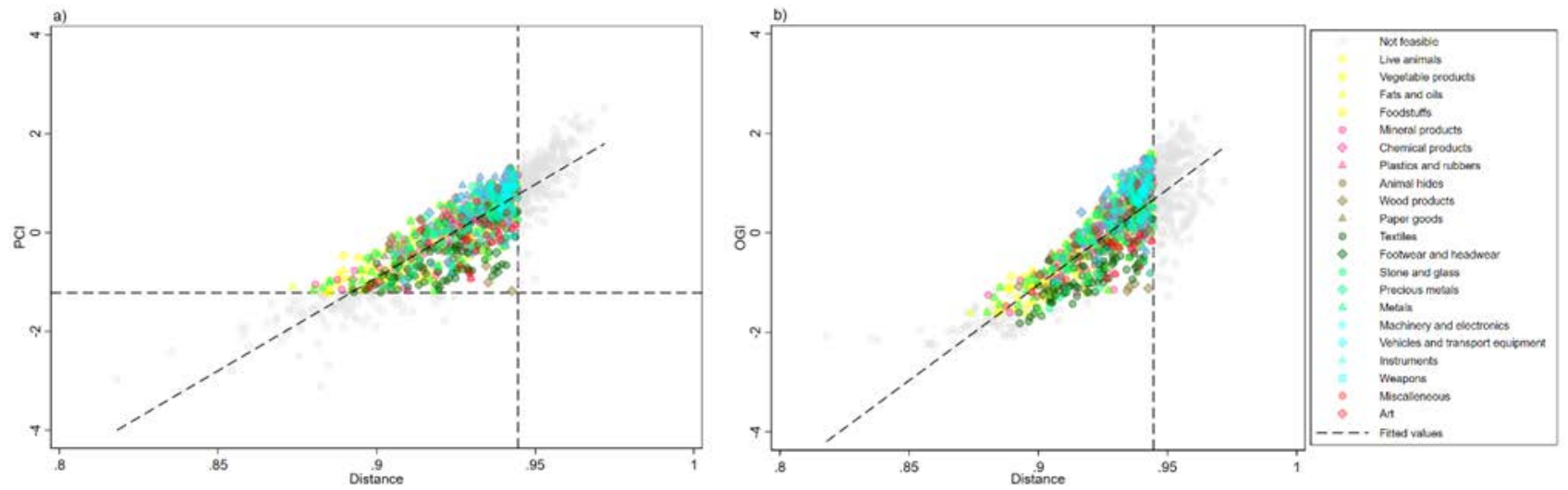

Source: authors' calculations based on trade data from Growth Lab (2019). 


\section{Choosing a weighting scheme}

The filtering process described above is clearly inadequate. While it narrows down Mozambique's feasible product space to a set of 731 attractive products, it is too broad for meaningful policy targeting. Therefore, it is necessary to devise an identification procedure to select a smaller number of 'target products' from the pool of 'feasible products'. One intuitive way to do this is to focus exclusively on products lying above the fitted lines in Figure 5. Investing in a product lying under the line is inefficient, as it would always be possible invest in another product located at a similar distance with a higher PCI/ OGI. This approach is, however, still too broad, classifying 388 products as feasible. Furthermore, such an approach does not take an active stand on whether Mozambique should put a higher value on a low distance, a high PCI, or a high OGI.

Following the approach adopted in the literature (see for instance Hausmann and Chauvin 2015; Hausmann et al. 2014, 2019), we address these issues by assigning a weight to each variable. The weighting scheme approach entails creating a new index in which each products' score is computed based on a weighted sum of the normalized values of distance, PCI, and OGI. Normalizing the variables makes it possible to compare the variables directly and assign an importance to each through weights. ${ }^{7}$ In this way, it is possible to reduce the dimensionality of the problem and conduct a comparison at the product level. Note that when we talk about assigning a weight to distance, we are in fact assigning a weight to its inverse-density-measuring Mozambique's closeness to a product. From the new summary index it is possible to select any number of target products, always including the products that score highest in the index. Specifically, we create two indexes based on two weighting strategies — a Leverage \& Support strategy and a Diversify \& Scale strategy-picking the 25 most important products from each (see Table 1).

Table 1: Weighting scheme

\begin{tabular}{|c|c|c|c|c|}
\hline \multirow[t]{2}{*}{ Strategy } & \multirow[t]{2}{*}{ Component } & \multicolumn{3}{|c|}{ Weights } \\
\hline & & Distance & $\mathrm{PCl}$ & OGI \\
\hline \multirow{2}{*}{$\begin{array}{l}\text { Leverage \& Support } \\
(0.1<\mathrm{RCA}<1)\end{array}$} & Low-hanging fruits & 0.45 & 0.25 & 0.30 \\
\hline & Strategic bets & 0.20 & 0.20 & 0.60 \\
\hline \multirow{2}{*}{$\begin{array}{l}\text { Diversify \& Scale } \\
(R C A<0.1)\end{array}$} & Low-hanging fruits & 0.65 & 0.15 & 0.20 \\
\hline & Strategic bets & 0.50 & 0.10 & 0.40 \\
\hline
\end{tabular}

Source: authors' construction.

The main issue with the weighting scheme approach lies in the selection of feasible weights. Previous studies sharing our approach have constructed weighting schemes more or less arbitrarily (see for instance Hausmann et al. 2017). As no better selection strategy is currently available we follow this approach, but we find it necessary to stress that the choice of weights in this paper remain more an art than a science-they stem from a somewhat subjective and political choice.

${ }^{7}$ Specifically, we apply the following normalization procedure:

$$
\operatorname{var}_{p}^{\text {norm }}=\frac{\operatorname{var}_{p}-\operatorname{var}^{\text {mean }}}{v a r^{\text {sd }}}
$$

where $v a r_{p}$ denotes the non-normalized value of distance, PCI, or OGI for product $p . v a r_{p}^{n o r m}$ is the normalized value of $v_{a r}$. var mean and $v a r^{s d}$ are the mean and standard deviation of $v a r$, respectively. The normalization gives each variable (distance, PCI, and OGI) a mean of 0 and a standard deviation of 1 . 
We motivate the choice of weights by three simple propositions informed by theory, empirical analyses, and Mozambique's industrial strategy. These are described below. To be as transparent as possible, we conduct a volatility analysis showing how the choice of target products varies with changing weights, described in the last subsection of the supply-side analysis.

Proposition 1: It is easier for Mozambique to develop a comparative advantage in a product if it already exports that product (without an RCA). Furthermore, distance matters less for Mozambique's ability to gain a comparative advantage in a product if it already exports that product non-competitively. Therefore, Mozambique should employ two weighting schemes. One weighting scheme should target products where Mozambique has no current exports, giving a higher weight to nearby products. We call this weighting scheme the Diversify \& Scale strategy as it focuses on identifying completely new product sectors that Mozambique can diversify into. Another weighting scheme should target products that Mozambique currently exports noncompetitively, where distance has a smaller weight and PCI and OGI are weighted higher. We call this second weighting scheme the Leverage \& Support strategy because it focuses on identifying, leveraging, and supporting the capabilities that already allow Mozambique to export certain products with an RCA below 1.

Proposition 1 is rooted in the simple idea that market actors can be assumed to have better information than the state about the potential for exporting new products in Mozambique. The analysis in this paper does not change this. Therefore, industrial policies should utilize market signals to identify product sectors that show export potential and then address the key constraints and enablers necessary to develop a comparative advantage in these sectors.

We test the intuition behind Proposition 1 in Table 2. It shows the results from a linear probability model predicting product appearances between 2015 and 2018 based on 2014 values of distance and a dummy variable, $D^{\text {Export }}$, taking the value 1 if Mozambique's RCA in a product was between 0.1 and 0.99 in 2014. The dependent variable, product appearances, takes the value 1 if a product was absent $(\mathrm{RCA}<1)$ from a country's export basket in year $t-1$ but appeared $(\mathrm{RCA}>1)$ in year $t$. We run the regression only on products that were absent in 2014. The model fits our intuition. Column 1 shows that countries are less likely to move into distant products, but more likely to gain a comparative advantage in a product, if they are already exporting that product noncompetitively. In the regression, we have standardized the distance variable to have a mean of 0 and a standard deviation of 1 . Thus, a country that is one standard deviation further away from a product has a 0.03 lower probability of starting to export that product with a comparative advantage over the coming four years. In the second column, we introduce an interaction term, showing that the negative effect of distance on product appearance is less pronounced if the product is already exported in a country.

In order to reduce noise and actually measure whether a product is already established in a country, we let $D^{\text {Export }}$ equal 1 only if $0.1>$ RCA $<1$. To check the robustness of the coefficient of the interaction term with respect to this cut-off, Figure 6 displays the coefficient plot for varying cutoffs. The plot indicates that the interaction term remains positive and significant (at the 1 per cent level) with a cut-off above 0.1 . We will therefore use the 0.1 cut-off to distinguish between products in our two weighting strategies. For products with $0.1>\mathrm{RCA}<1$, we give a lower weight to distance. It should be noted that by setting a threshold as low as 0.1 to classify established export industries, we run the risk of assuming that Mozambique has capabilities in products that are in fact not produced in the country, but are imported and re-exported. We do not have data to directly check for re-exports and the results in our analysis should therefore be interpreted with this caveat in mind. The positive and significant coefficient in Table 2 does, however, provide evidence that on average countries find it easier to jump long distances when they already have exports above this 
RCA cut-off. Guided by these results, we find it reasonable to assume that exports with an RCA above 0.1 are indicative of established export capabilities in that product.

Table 2: Effect of current exports and distance on product appearances

$$
\text { Product appearances (2015-18) }
$$

(1)

\begin{tabular}{lrr} 
Distance (2014) & $-0.030^{\star \star \star}$ & $-0.031^{\star \star \star}$ \\
& $(0.001)$ & $(0.001)$ \\
$D^{\text {Export }}(2014)$ & $0.025^{\star \star \star}$ & $0.025^{\star \star \star}$ \\
& $(0.001)$ & $(0.001)$ \\
Distance $\times D^{\text {Export }}(2014)$ & & $0.002^{\star \star \star}$ \\
Year FE (fixed effects) & & $(0.001)$ \\
Country FE & YES & YES \\
Observations & YES & YES \\
R-squared & 527,008 & 527,008 \\
\hline
\end{tabular}

Note: robust standard errors in parentheses; ${ }^{\star \star \star} p<0.01,{ }^{\star \star} p<0.05,{ }^{*} p<0.1$; constant not reported; the value of Distance has been standardized.

Source: authors' calculations based on trade data from Growth Lab (2019).

Figure 6: Coefficient plot of Distance $\times D^{\text {Export }}$ interaction term

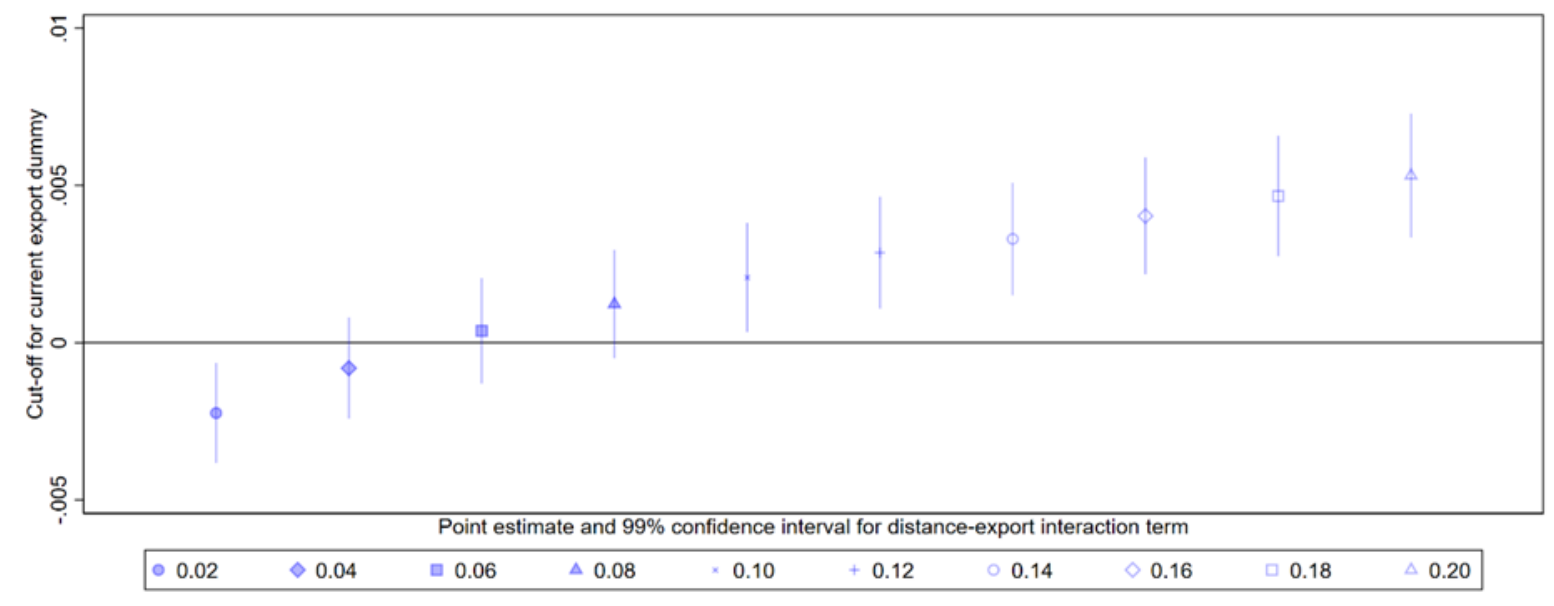

Note: shows point estimates and 99\% confidence intervals for distance-export interaction terms with different $D^{\text {Export }}$ cut-off points. Each estimate is calculated by running the same regression as in Column 2, Table 2, but with different cut-off points for $D^{\text {Export }}$.

Source: authors' calculations based on trade data from Growth Lab (2019).

Proposition 2: Industrial policy in Mozambique needs to strike a balance between the policy objective of relatively quick and low-cost implementation and the potential for higher pay-offs in the future. To strike this balance, the weighting strategy should be split into a 'low-hanging fruits' component, where distance and PCI has a higher weight, and a 'strategic bets' component, valuing long jumps into highly high-OGI products. 
On one hand, Mozambique's industrial policy favours industries 'whose implementation and resource allocation can develop relatively quickly' (GoM 2014b). A strategy focusing on nearby products with (relatively) high PCI scores is likely to satisfy this policy objective. First, the strategy should put a high weight on distance. Since Mozambique already possesses some of the capabilities necessary to move into nearby products, the cost of investing in the few missing links is relatively small. Furthermore, the timeline for a structural transformation process allocating factors of production to higher-complexity activities in nearby products is likely to be shorter because the productive structure of the economy does not need to change dramatically. Second, the strategy should put a relatively higher weight on high-PCI products, because these will increase Mozambique's complexity immediately. High-OGI products, on the other hand, influence the prospects of future diversification but do not necessarily deliver a complexity premium themselves.

On the other hand, theory prescribes that Mozambique experiment with the development of comparative advantages in dense parts of the product space further away from its current productive structure. This argument is based on the idea that the strategic focus of industrial policy should take into account that different countries are positioned differently with respect to their opportunity to (i) diversify and upgrade and (ii) achieve economic growth (Growth Lab 2020; Hausmann et al. 2016). Figure 7 plots countries along these two spectra. The y-axis measures how close countries are to not-yet-produced, complex products in the product space (COI). The x-axis measures how much countries are projected to grow, given their current GDP per capita and ECI (measured by residuals when regressing ECI on the log of GDP per capita). ${ }^{8}$

Figure 7: Strategic approach

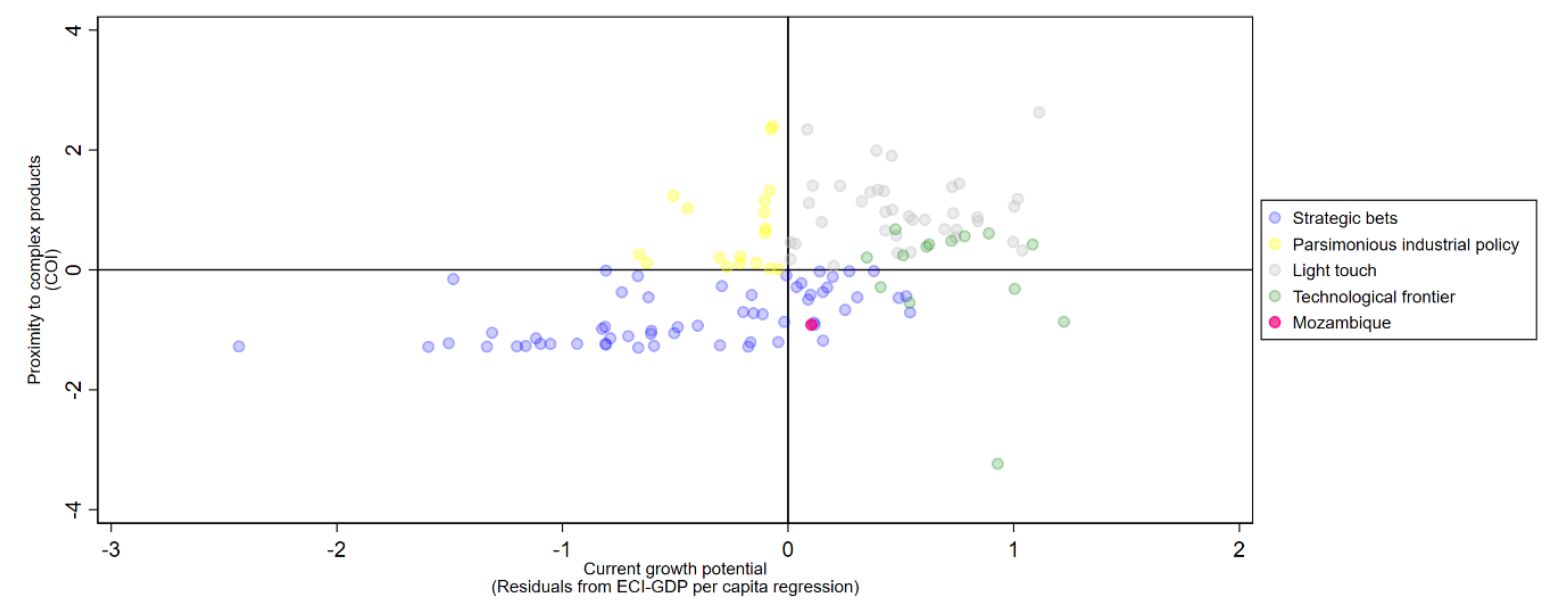

Source: authors' calculations based on trade data from Growth Lab (2019).

Countries in the upper-left quadrant of this two-by-two matrix should pursue a parsimonious industrial policy. These countries are projected to grow slowly, as they currently have a higher GDP per capita than is warranted by their ECI. Luckily, however, the countries are located close to many complex products, and their main aim should therefore be to leverage this position in order to increase their complexity. For these countries, PCI should have a relatively higher weight. Countries in the upper-right corner are placed in a 'sweet spot' close to many complex products and yet are already complex enough to grow in the future. Here, governments should apply a lighttouch approach, with a balanced weighting strategy. The countries coloured in green are highly complex countries (in the 90th percentile in terms of ECI). Having exhausted most possibilities

\footnotetext{
${ }^{8}$ In contrast to Figure 2d, positive residuals from this regression are indicative of higher economic growth rates.
} 
for diversification and upgrading, these countries' technological frontier approach should focus on innovation, developing entirely new products. Finally, countries placed in the lower two quadrants of the matrix are located in the outskirts of the product space, far from any complex cluster of products. These countries should follow a strategic bets approach, experimenting with long jumps into well-connected parts of the product space. Thus, these countries should prioritize OGI over distance and PCI (relative to other strategies) (Growth Lab 2020; Hausmann et al. 2016). Mozambique, depicted in blue, should follow this strategic bets approach.

Proposition 3: Market actors have an incentive to move into highly complex products, but a weaker incentive to move into products connected to other complex products (high-externality products). Because market actors can be expected to internalize the value of PCI, but OGI to a lesser extent, our weighting scheme should, as a general rule of thumb, put a higher weight on OGI.

Consider the simple model developed in Hausmann and Klinger (2006b), where a firm can either stick to producing product $p$ or jump to a new product $p^{\prime}$. The firm has an incentive to jump, if it can earn a higher price by producing product $p^{\prime}$. We can assume this is the case if $P C I_{p^{\prime}}>P C I_{p}$. However, the firm will also face a fixed cost of jumping from $p$ to $p^{\prime}$, because it has to acquire the new capabilities necessary to produce product $p^{\prime}$. This fixed cost increases with the distance between the products, $d_{p, p^{\prime}}$. The firm only jumps if the benefits of doing so outweigh the costs. ${ }^{9}$ However, it might be socially optimal if the firm jumps even if it incurs a loss, if externalities reduce the cost of jumping into the same or related products for emulating firms. Such spillovers occur, for instance, through labour mobility. ${ }^{10}$ Because the societal value generated by investing in a new product is not fully appropriated by the original firm, under-investment is likely to occur in the competitive equilibrium. ${ }^{11}$ In order to spur externalities and reach socially optimal investment levels, industrial policies should put a higher weight on the factors that the market does not value appropriately (OGI). ${ }^{12}$

We take this idea to the data in Table 3. It shows the results from the linear probability model described above, but with 2014 values of distance, PCI, and OGI as explanatory variables. All variables are standardized and the interpretation of the coefficients is as described for Table 2 above. As we would expect, when holding distance constant, countries are more likely to move into products with high PCI scores. The same is not true for OGI. The negative coefficient shows that the probability of moving into a new product is negatively correlated with OGI. This confirms that OGI should be weighted higher than PCI.

\footnotetext{
${ }^{9}$ Empirically, product switching has been shown to be substantial in the US (Bernard et al. 2010), but in a developingcountry context results are more unclear (Goldberg et al. 2010; Newman et al. 2013).

${ }^{10}$ Imagine if the firm wants to produce non-alloy steel in a country that has not done so before. It may have to invest heavily in the training of mechanical engineers to operate the smelters. These engineers may later be hired by emulators, when they realize that it is profitable to produce non-alloy steel in the country. The engineers may also be hired by another firm capitalizing on the local supply of non-alloy steel to make wrought iron products in the country.

${ }^{11}$ A slightly moderated version of the model is found in Hausmann and Klinger (2007). The main conclusion remains intact.

${ }^{12}$ Notice that market actors are likely to assign some (inadequate) value to high-OGI products. If a firm plans to jump into several new products sequentially, it has an incentive to land the initial jumps in products that are better connected to other highly complex products. Because the model of Hausmann and Klinger (2006b) is one of overlapping generations considering only two time periods, it does not explicitly address this scenario.
} 
(1)

$$
-0.043^{\star \star \star}
$$

PCI (2014)

OGI (2014)

\section{Year FE}

Country FE

Observations

R-squared
(2)

(3)

Note: robust standard errors in parentheses; ${ }^{* *} p<0.01$, ${ }^{*} p<0.05$, ${ }^{*} p<0.1$; constant not reported; the values of distance, $\mathrm{PCl}$, and $\mathrm{OGI}$ have been standardized.

Source: authors' calculations based on trade data from Growth Lab (2019).

Based on Propositions 1, 2, and 3, we adopt the weighting strategies shown in Table 1. Following Proposition 1, the strategy takes into account that Mozambique should have two overall strategies - a Leverage \& Support strategy focused on already-exported products and a Diversify \& Scale strategy focused on developing completely new products. A higher weight is given to distance in the latter strategy. Based on Proposition 2, we split each strategy into a strategic bets and a low-hanging fruits component in order to balance a long-term strategic focus with the objective of easier implementation and a quick transition. We assign relative high weights to distance and PCI in the latter component. Finally, because of the large externality component in OGI, our approach always assigns higher weights to OGI compared with PCI.

\section{Target products}

We identify 25 products from each of the four strategy-component combinations listed in Table 1. Because the low-hanging fruits and strategic bets components of each strategy identify some of the same target products, we end up identifying 84 target products for Mozambique. Figures 8 and 9 show these 84 target products, while Figure 10 counts the total number of target products identified within each product section. Tables A1-A4 in the appendix provide the full list of products for each strategy-component combination.

Figure 8 shows that the Leverage \& Support strategy identifies products from a broad set of sectors. Mozambique is already exporting these products. Thirteen of the products identified in the low-hanging fruits and strategic bets components are identical. This is a consequence of the fact that only 121 of the products Mozambique exports with $0.1<\mathrm{RCA}<1$ lie within the feasibility space defined in Figure 5 (for an extended discussion, see the subsection on robustness checks below). Many of the target products have a high OGI score as well as a PCI level far beyond Mozambique's ECI. This indicates that Mozambique is already exporting some high-complexity products, although it does not currently have a comparative advantage in them. Products in the machinery and electronics section account for 12 of the 37 products collaboratively identified by the two components of the strategy. The remaining two-thirds of the target products are broadly allocated between product sectors. 


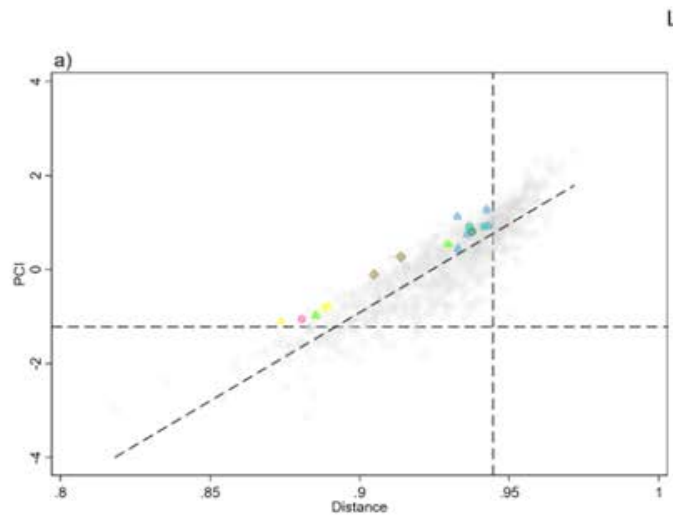

Low-hanging fruits component
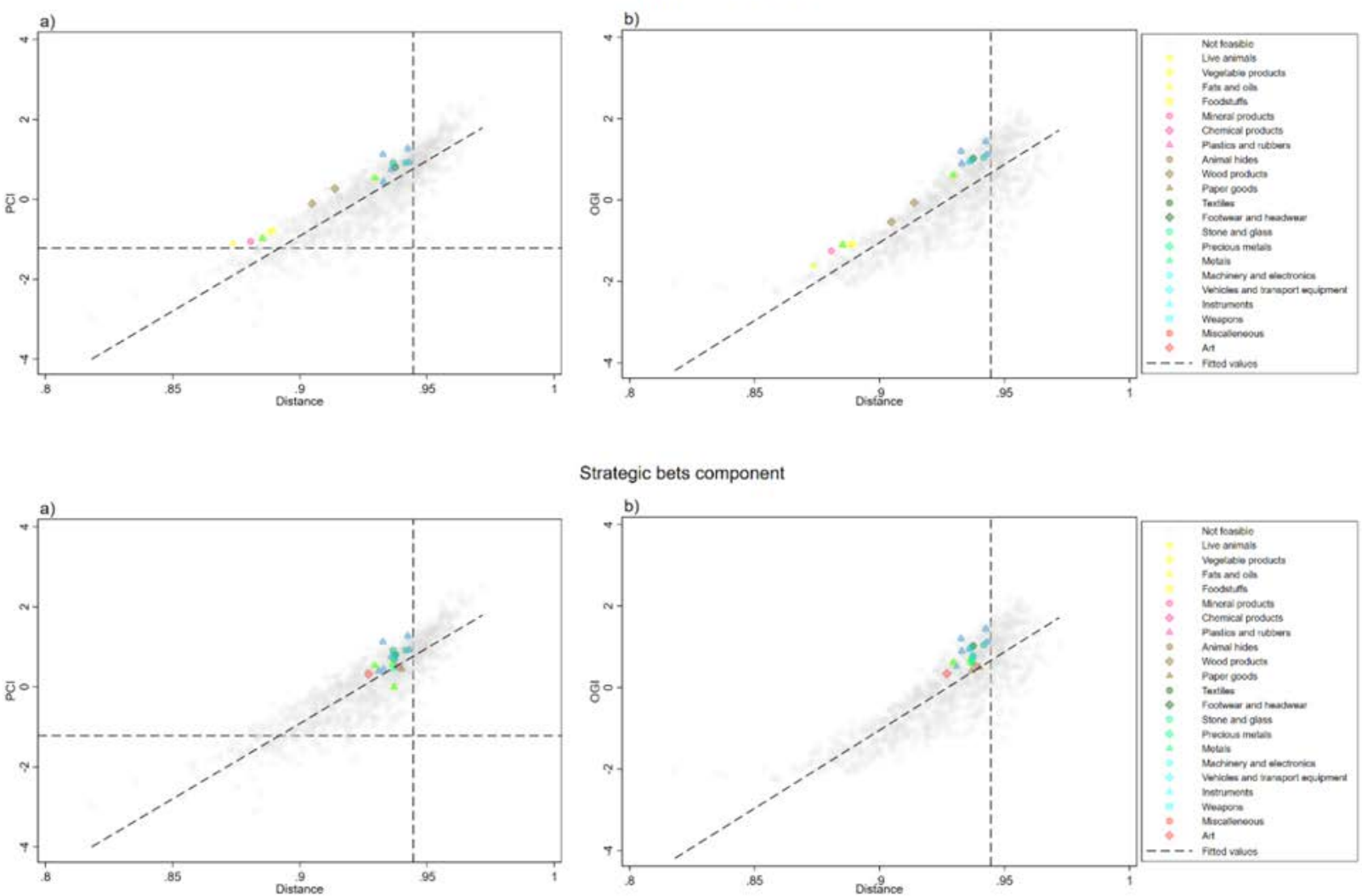

Strategic bets component

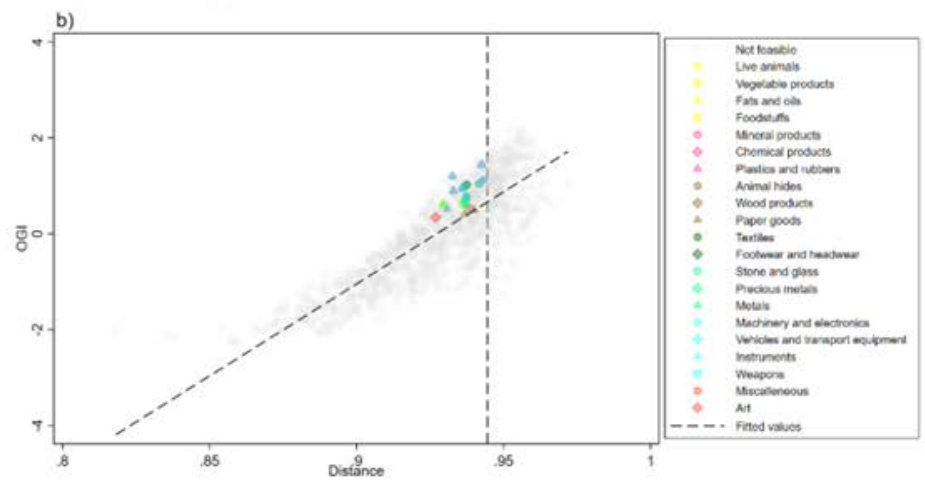

Source: authors' calculations based on trade data from Growth Lab (2019).

Figure 9 displays the target products identified with the Diversify \& Scale strategy. Mozambique currently has an RCA $<0.1$ in these products. The most prominent product sector identified in the low-hanging fruits component is agriculture and agro-industry, accounting for 19 products within foodstuffs (6), live animals (6), vegetable products (6), and animal hides (1). These products are only slightly more complex than Mozambique's average complexity, but they lie close to the country's productive capabilities. The strategic bets component of the Diversify \& Scale strategy identifies an entirely different set of products. These are of high complexity and are located further away from Mozambique's location in the product space. Machinery and electrical equipment constitutes the biggest product section, with eight target products, followed by three target products in metals and vehicles and transport equipment. We note that both sets of products are located at Mozambique's 'efficiency frontier', having large and positive residuals when fitting a linear line through the scatter plot. 

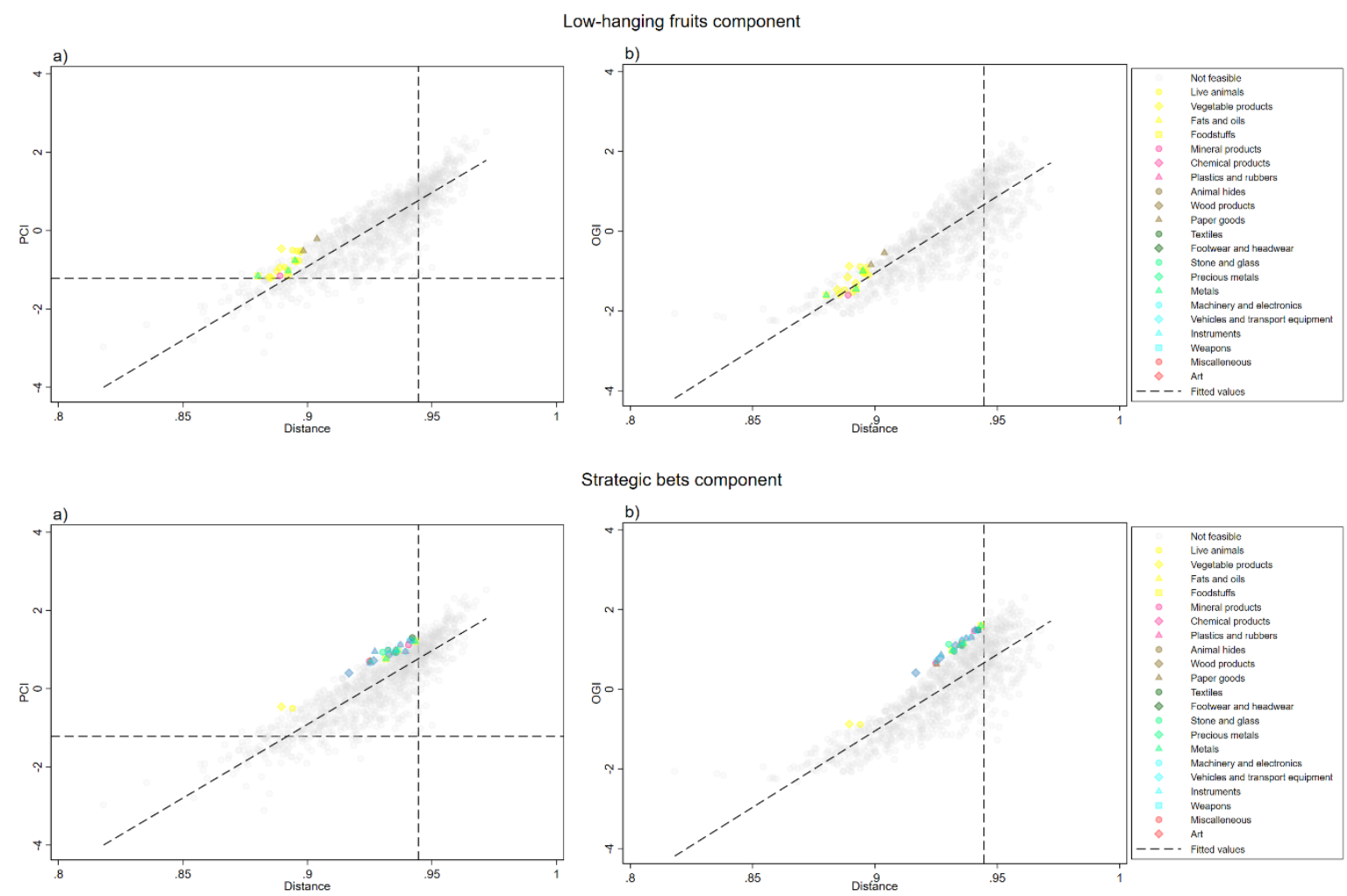

Source: authors' calculations based on trade data from Growth Lab (2019).

Figure 10 displays the total number of target products identified by the Leverage \& Support and Diversify \& Scale strategies within each sector. On one hand, the figure highlights that Mozambique's current industrial policy focus on multiple different sectors is warranted. The country needs to diversify production, not to specialize in a narrow set of industries. Although this strategy runs contrary to traditional trade models' call for specialization, it is in line with recent empirical evidence that diversification is related a country's growth paths and level of income (Cristelli et al. 2013, 2017; Hausmann et al. 2013).

On the other hand, Figure 10 provides an idea about which specific sectors constitute important pillars for structural transformation in Mozambique and allows us to compare these target sectors to the seven priority sectors identified in the Industrial Policy and Strategy 2016-2025. The comparison can be broken into three parts. First, we identify machinery and electronics, vehicles and transport equipment, and instruments as sectors that seem highly important but that are left out of Mozambique's current industrial strategy. These products have particularly high PCI scores and are located in a dense cluster of the product space. It may seem far-fetched that Mozambique should bet on these highly sophisticated industries that lie far from the country's current productive know-how. However, many of the target products identified in these sectors have been identified with the Leverage \& Support strategy, meaning that Mozambique is already exporting them. Understanding how industrial policy can leverage and support the capabilities that already allow Mozambican firms to produce and export these products is therefore an important policy exercise. 


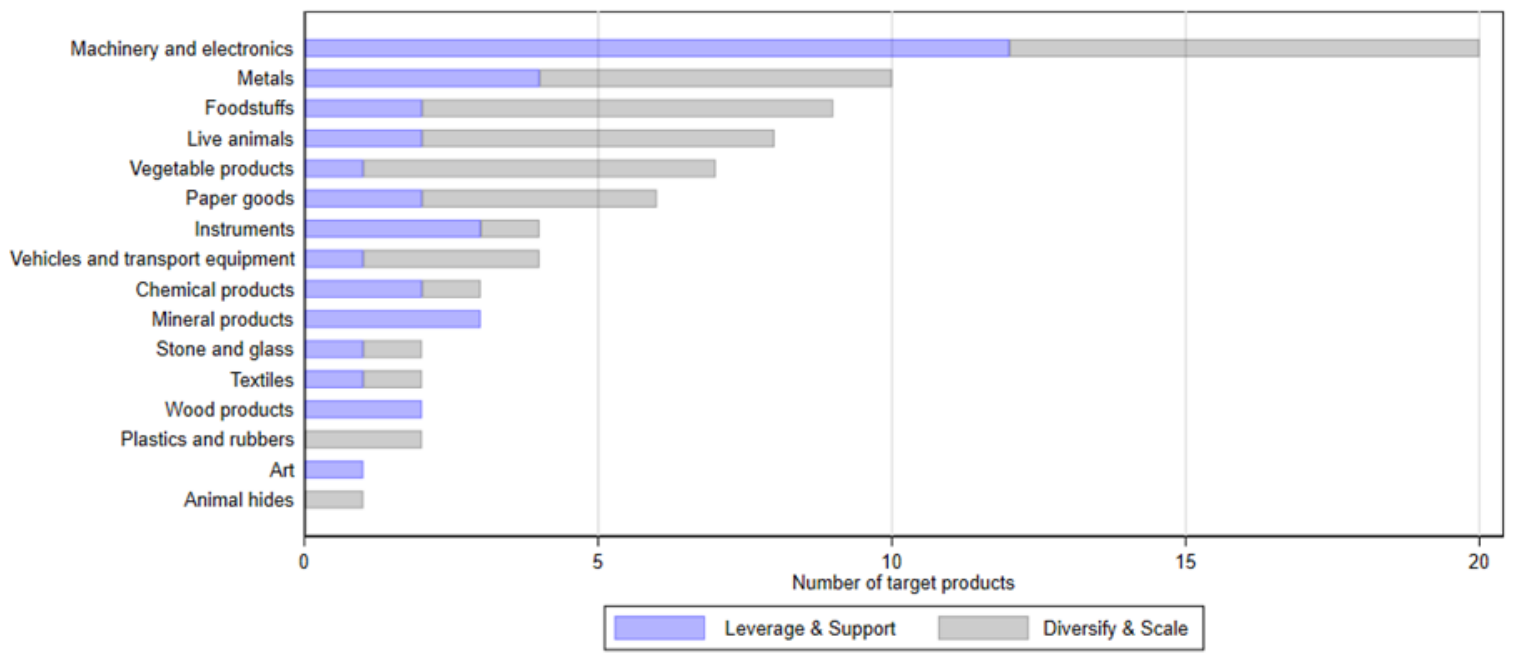

Source: authors' calculations based on trade data from Growth Lab (2019).

Second, Agro-processing (foodstuffs), metals, and paper goods constitute very important transformation drivers and are simultaneously included as priority sectors in the Industrial Policy and Strategy 2016-2025. In fact, agricultural production in general seems to constitute an important pillar in structural transformation efforts, accounting for a total of 25 target products (foodstuffs: 9, live animals: 8 , vegetable products: 7, animal hides: 1). These conclusions are in line with those reached through CGE modelling in previous studies (Arndt et al. 2010; Hartley et al. 2019; Jensen and Tarp 2004). Metals is already a significant part of Mozambique's export basket (see Figure 2). This export volume is, however, almost exclusively driven by aluminium ingot production from the Mozal aluminium smelter (Sutton et al. 2014). Our analysis highlights that diversification of metal exports has a huge potential to drive transformation in Mozambique. One way to do this is to build on the last decades' successful policies aiming to establish supply-chain linkages from Mozal to the local economy. Examples include the SME Empowerment Linkage Program, MozLink, and MozLink II_-programmes aiming to link local small and medium-sized enterprises (SMEs) to the construction and operation phases of Mozal. Today, a large part of Mozambique's metal sector stems from SMEs in Mozal's supplier network (Sutton et al. 2014). The literature on FDI highlights that such linkages may facilitate learning spillovers and technology transfers, with the potential to help local firms develop export capabilities in other parts of the metal sector (Bajgar and Javorcik 2020; Eck and Huber 2016; Javorcik 2004; Javorcik et al. 2018; Moran 2007; Newman et al. 2015; Sørensen 2020).

Third, the priority given to non-metallic minerals; chemistry, rubber, and plastics; clothing, textiles, and footwear; and wood and furniture is broadly in line with the results from the analysis in this paper. Accounting for 15 target products (minerals and stone and glass: 5, chemicals and plastics and rubbers: 5 , textiles: 2 , wood products: 2 ), these sectors are not as prominent as those described above, but they are not completely irrelevant either. The export of mineral fuels is the single largest export category in Mozambique today (see Figure 2). But despite their enormous share in Mozambique's current export revenue, mineral fuels hold relatively few opportunities to ignite structural transformation going forward. Minerals are generally poorly connected to other products and of relatively low complexity. The limited transformative power of this sector has already been noted in Dietsche and Esteves (2018). Finally, it is noteworthy that the weighting scheme does not identify any footwear products. Thus, from a complexity point of view, this component of the textile sector should not be included as a priority in Mozambique. 


\section{Robustness check}

We conduct a volatility simulation to shed light on the impact of the choice of weights on the selection of target products. Figure 11 presents four bivariate histograms displaying the cooccurrence of selected target products between each of the four strategy-component combinations and other potential weighting schemes. In other words, the histograms display the overlap in target products between all possible weighting schemes and each of our four strategy-component schemes. For instance, the strategic bets component of the Leverage \& Support strategy identifies seven target products similar to an extreme strategy putting close-to-exclusive weight on distance.

The simulation shows that the ratio of the weights assigned to OGI and PCI has only a small impact on the target product selection, when holding the distance-weight constant. This is true across all four strategy-component combinations and is a consequence of the strong positive correlation between OGI and PCI (typically, more connected products are also more complex). In contrast, there is a discontinuous jump in the products identified as targets when the weight given to distance changes around 0.5. Except for those in the low-hanging fruits component of the Leverage \& Support strategy, the target products changes more or less completely when crossing the cut-off point.

The documented volatility is not a weakness of our analysis per se. In fact, we would expect the selection of target products to be correlated with the choice of weights: the essence of the weighting scheme approach is to select some products over others given their characteristics. Moreover, it is important to note the strategic interplay between our choice of weights and the discontinuous jump around the 0.5 cut-off point for the distance-weight. The low-hanging fruits and strategic bets components of the Diversify \& Scale strategy are respectively meant to capture proximate products of lower PCI/OGI and distant products of higher PCI/OGI. Because the components of the Diversify \& Scale strategy give distance a weight on either side of the cut-off point, we capture exactly these two different groups of target product. Conversely, with the Leverage \& Support strategy we want to exploit the fact that it is easier to develop a comparative advantage in products that are already exported (see Table 2 and Figure 6), and we are therefore primarily interested in capturing highly complex and connected-but distant-products. Consequently, we assign a distance-weight below the cut-off in both components of the Leverage \& Support strategy.

At a more general level, the simulations raises questions about the robustness of the conclusions one can reach by applying a single weighting strategy, and they explain why it is common in the literature to propose a set of different weighting schemes (Hausmann and Chauvin 2015; Hausmann and Klinger 2006a; Hausmann et al. 2016, 2017, 2019). 

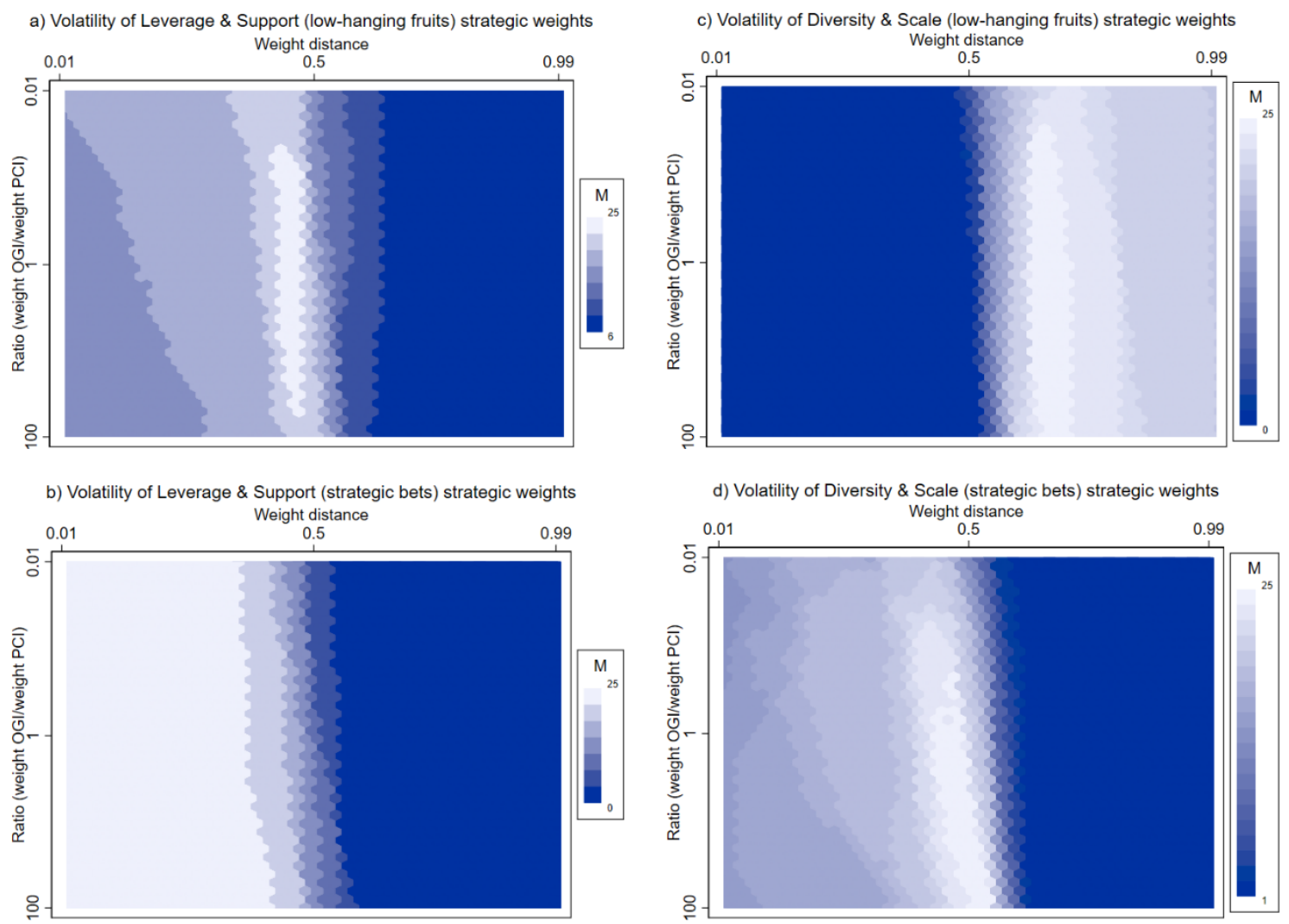

Note: the figure shows bivariate histograms of the target product overlap between various arbitrary weighting schemes and the target products chosen by (a) the Leverage \& Support strategy (low-hanging fruits), (b) the Leverage \& Support strategy (strategic bets), (c) the Diversify \& Scale strategy (low-hanging fruits), and (d) the Diversify \& Scale strategy (strategic bets).

Source: authors' calculations based on trade data from Growth Lab (2019).

\section{Demand-side analysis}

The analysis thus far has focused on the supply side of Mozambique's structural transformation challenge. This section extends the analysis to take into account demand-side factors. Specifically, the section analyses (i) which target products are likely to generate the highest export revenue and (ii) which countries constitute the biggest export markets for these products. The analysis is based on a simple gravity model framework that accounts for product-specific factors (such as transportation costs), import market factors (such as product-specific demand), and exporterimport relevant factors (such as the physical distance between countries).

\subsection{Data}

The demand-side analysis builds on four data sources. First, we use importer-exporter-productlevel trade data for 2011-18 from United Nations Statistical Division (COMTRADE), compiled and cleaned by the Growth Lab at Harvard University (Growth Lab 2019). We 'square' the dataset, inserting zeroes for all missing exporter-importer-product combinations. This gives us a starting point of 555,740,352 observations. Because we run our gravity model at the product level-and only for our target products-we exclude all non-target products from the sample. Second, we obtain various inter-country distance measures and indicators for landlocked countries from the 
GeoDist database compiled by the Centre d'Études Prospectives et d'Informations Internationales (CEPII; Mayer and Zignago 2011). Third, we use the CEPII Gravity dataset (CEPII 2015) to get information on regional trade agreements from 2011 to 2015 as reported by the World Trade Organization (WTO). We update this variable with data for 2016-18 from the WTO's website (WTO 2020). Finally, GDP measures are taken from the World Development Indicators (World Bank 2020). Countries that cannot be linked to all datasets are then dropped, along with Chad, Iraq, and Macau (for which the export data are unreliable). ${ }^{13}$ The final dataset contains 25,421,760 observations, based on 195 countries and the 84 target products identified in the supply-side analysis.

\subsection{Methodology: gravity model}

\section{Estimating the gravity model}

The aim of the demand-side analysis is to estimate a predicted trade volume for the different target products and to the different export markets. We start from a structural gravity model, following Head and Mayer (2014): ${ }^{14}$

$$
T_{i n t}=\frac{Y_{i t}}{\vartheta_{i t}} \frac{X_{n t}}{\varphi_{n t}} \emptyset_{i n}
$$

where $T_{\text {int }}$ denotes the value of trade from exporter $i$ to importer $n$ in year $t . Y_{i t}$ is the value of exporters' production and $X_{n t}$ the value of importers' expenditures in year $t$. $\vartheta_{i t}$ and $\varphi_{n t}$ are multilateral resistance terms, while $\emptyset_{\text {in }}$ is a term for bilateral accessibility.

We estimate Equation 14 in its multiplicative form with the Poisson pseudo-maximum-likelihood (PPML) estimator, using fixed effects to control for exporters' output, importers' expenditure, and their respective multilateral resistance terms. We estimate the model separately for each target product $p$ to fix the analysis at the product level and allow for product-specific slope parameters and fixed effects (different products are, for instance, likely to have different slope parameters for dyadic distance because their transportation costs vary). The PPML regression model can be written as:

$$
T_{i n t}^{\{p\}}=\exp \left(\alpha^{\{p\}}+\boldsymbol{\beta}^{\{\boldsymbol{p}\}^{\prime}} \boldsymbol{I n} \emptyset_{i n}+\gamma_{i t}^{\{p\}}+\theta_{n t}^{\{p\}}\right) \times \varepsilon_{i n t}^{\{p\}}
$$

where $\emptyset_{\text {in }}$ is a vector of distance measures between importer $n$ and exporter $i$. The model includes the log of physical distance between countries' most populated cities and a set of indicator variables for contiguity (sharing a border), colonial ties, if a language is spoken by at least 9 per cent of the population in both countries, and whether two countries are part of the same regional trade agreement. $\gamma_{i t}$ and $\theta_{n t}$ are exporter-year and importer-year fixed effects.

\footnotetext{
${ }^{13}$ This contrasts with the stricter cleaning procedure we applied in the supply-side analysis in order to reduce noise and estimate the complexity values reliably. There are several reasons behind this choice. First, the complexity variables are sensitive to the inclusion of very small countries that export little. The gravity model is not sensitive to the same extent. Second, many small Sub-Saharan African countries were excluded from the supply-side dataset because they exported less than US $\$ 1$ billion on average from 2014 to 2017. By leaving in all countries in the sample, we make sure that we can granularly identify potential export markets for Mozambique.

${ }^{14}$ As we work with panel data, we add the subscript $t$ to the model.
} 
Table 4 displays the average point estimates and standard errors across all 84 iterations of Model 15 (one for each target product). The average coefficients and standard errors of our preferred specification (PPML with exporter-year and importer-year fixed effects) are shown in Column 4. For comparison, we also estimate the gravity model by linear-in-logs ordinary least squares (OLS) and without fixed effects to control for $\frac{Y_{i t}}{\vartheta_{i t}}$ and $\frac{X_{n t}}{\varphi_{n t}}$. We show results from OLS regressions in Columns 1 and 2. While the log-linearized OLS regression has long been the workhorse in the empirical gravity literature, several advantages of the PPML estimator have recently been noted. First, Santos Silva and Tenreyro (2006) show that the PPML estimator is robust to different patterns of heteroscedasticity. In contrast, linear-in-logs OLS estimates can be severely biased under heteroscedasticity. Second, the PPML model allows for easy incorporation of zero values in the dependent variable and produces consistent estimates even when the share of zeroes is large (Santos Silva and Tenreyro 2011). OLS estimation does not allow for the incorporation of zeroes due to the logarithmic transformation of the trade flows (zero values will be undefined). As a consequence, the OLS estimations displayed in Columns 1 and 2 of Table 4 discard the majority of observations in our dataset and may be biased. ${ }^{15}$ Finally, estimating the gravity equation with PPML and fixed effects automatically produces predicted export flows, whose sum adds up the trade flows observed in the data (Fally 2015).

Results from 'traditional' (or 'naive') gravity regressions without importer-year and exporter-year fixed effects are reported in Columns 1 and 3. This approach involves the inclusion of proxies for $Y_{i t}$ and $X_{n t}$ as well as $\vartheta_{i t}$ and $\varphi_{n t}$. We follow the strategy in Santos Silva and Tenreyro (2006) and include (the log of) importers' and exporters' GDP and GDP per capita, measures of their remoteness, and dummies indicating whether they are landlocked. ${ }^{16}$ The remoteness variables proxy for the multilateral resistance terms. The best-in-class remoteness proxies are calculated as $\left(\sum_{n t} \frac{G D P_{n t}}{\text { Distance }_{n i}}\right)^{-1}$ for exporter remoteness and $\left(\sum_{i t} \frac{G D P_{i t}}{\text { Distance }_{i n}}\right)^{-1}$ for importer remoteness (Head and Mayer 2014). We take the log of these variables in our gravity equation so their coefficients can be interpreted as elasticities. We expect the sign of the coefficients to be positive based on the intuition that greater distance to all other countries will increase trade between two countries. It should be noted, though, that remoteness variables are all inconsistent with the theoretical concepts of multilateral resistance (Head and Mayer 2014). Instead, the use of fixed effects to control for exporters' output, importers' expenditure, and their respective multilateral resistance terms is widely acknowledged as the theory-consistent gold standard in gravity estimation today (Head and Mayer 2014). The fixed effects estimates are shown in Column 2 and 4 of Table 4.

\footnotetext{
15 Some studies using linear-in-log OLS estimation keep zeroes by transforming the dependent variable as $\ln \left(T_{\text {in }}+1\right)$. This method should be avoided because the results will depend on the unit of measurement and the interpretation of coefficients as elasticities are lost (Head and Mayer 2014).

${ }^{16}$ While we follow the estimation strategy in Santos Silva and Tenreyro (2006) in broad terms, our approach deviates from theirs in certain respects. First, we run the regressions on the product level, not the country level. Second, we use panel data and therefore include year fixed effects in the 'traditional' gravity regressions. Third, we include the same control variables (except a dummy for trade openness), but we define some of them slightly differently. For instance, we use remoteness proxies argued to be more (but not completely) consistent with theory (Head and Mayer 2014).
} 
Table 4: Average coefficient estimates and standard errors across target products

$$
\begin{array}{cccc}
\text { OLS } & \text { OLS FE } & \text { PPML } & \text { PPML FE } \\
\ln \left(T_{i n t}^{\{p\}}\right) & \ln \left(T_{i n t}^{\{p\}}\right) & T_{i n t}^{\{p\}} & T_{i n t}^{\{p\}}
\end{array}
$$

$-0.81$

(2)

(3)

(4)

Distance

$(0.03)$

[0.05]

$-1.11$

$-0.68$

$-0.83$

(0.03)

(0.05)

[0.05]

[0.12]

(0.04)

Contiguity

$\mathbf{0 . 8 0}$

0.71

0.65

[0.09]

(0.07)

[0.16]

$(0.07)$

(0.10)

[0.15]

[0.26]

$\mathbf{0 . 5 2}$

(0.08)

0.15

0.40

$-0.05$

[0.19]

Common language

(0.05)

(0.05)

(0.08)

0.34

[0.10]

[0.10]

[0.21]

(0.08)

[0.19]

Colonial tie

0.42

0.63

0.30

$\mathbf{0 . 4 3}$

(0.07)

$(0.07)$

(0.11)

[0.15]

[0.26]

(0.08)

[0.16]

0.33

0.74

[0.20]

RTA

(0.04)

(0.05)

(0.08)

[0.09]

[0.19]

[0.09]

Exporter's GDP

0.62

0.88

(0.02)

$(0.01)$

[0.05]

0.51

0.72

Importer's GDP

(0.01)

[0.02]

(0.02)

[0.05]

0.05

$\mathbf{0 . 0 3}$

(0.02)

[0.04]

(0.04)

[0.09]

0.01

0.05

$(0.02)$

[0.03]

(0.03)

[0.08]

$\mathbf{0 . 0 1}$

$-0.04$

$(0.04)$

[0.08]

(0.08)

[0.19]

$\mathbf{0 . 4 5}$

0.32

(0.04)

[0.09]

(0.08)

[0.20]

$-0.20$

$-0.18$

(0.06)

(0.10)

[0.12]

[0.25]

$-0.27$

$-0.12$

(0.05)

(0.09)

[0.10]

[0.22]

Year FE

Importer-year FE

Yes

No

Yes

No
Yes

No

No

No

Yes

No

(0.07)

[0.15]

Note: dependent variable is trade volume (PPML) and log of trade volume (OLS) in the years 2011-18; coefficients and standard errors refers= to averages across 84 regressions (one for each target product); robust standard errors in parentheses; standard errors clustered at exporter-importer level in brackets.

Source: authors' calculations based on data from Growth Lab (2019), CEPII (CEPII 2015; Mayer and Zignago 2011), World Bank (2020), and WTO (2020), and as described in the data section. 
From Table 4, it can be seen that the signs of the coefficients are broadly in line with our expectations across all four specifications. ${ }^{17}$ However, the results also highlight that the choice of regression specification and estimator matters. When moving from the naive PPML (OLS) to the fixed effects PPML (OLS) regressions, the negative effect of distance on bilateral trade is 22 per cent $(37$ per cent) higher. This is a non-negligible change. The effects of sharing a common language and colonial ties also increase, whereas the border effect lessens. For the PPML regressions, the effect of regional trade agreements is higher in the fixed effects specification. We also note sizeable changes in coefficients when moving from the OLS to the PPML estimator. The effect of distance, for instance, decreases by 25 per cent (16 per cent) in the fixed effect (naïve) specification. The coefficients on contiguity, common language, and colonial ties also decrease. In contrast, the change in estimator increases the effect of regional trade agreements by over 100 per cent in both the naive and the fixed effects specifications.

In the preferred specification from Column 4, distance has a strong negative effect on trade volume. A 1 per cent increase in distance decreases the predicted volume of trade by 0.83 per cent. This effect is comparable to that reported by Santos Silva and Tenreyro (2006) using a PPML with fixed effects $(-0.75)$, but is slightly lower than the general finding in the literature of a negative elasticity around unity (Head and Mayer 2004, 2014; Redding and Venables 2004). The difference may be caused by Mozambique's target products having relatively low transportation costs. The average coefficients of contiguity and common language are also close to the estimates reported by Santos Silva and Tenreyro (2006). Yet, where Santos Silva and Tenreyro (2006) find no significant effect of colonial ties on bilateral trade, our estimates show that sharing a colonial past increases the trade volume between two countries by 54.15 per cent. ${ }^{18}$ Our estimated effect of regional trade agreements is also markedly larger than that reported by Santos Silva and Tenreyro (2006) (0.38 vs 0.67$)$.

\section{Predicting export potential}

We use the product-specific coefficients from each iteration of Equation 15 to predict the export potential of Mozambique's different target products and the market potential of the country's different trade partners. Specifically, let the predicted export value from Mozambique to an importer $n$ in product $p$ at time $t, \widehat{T}_{M o z, n t}^{\{p\}}$, be defined as:

$$
\widehat{T}_{M o z, n t}^{\{p\}}=\exp \left(\hat{\alpha}^{\{p\}}+\widehat{\boldsymbol{\beta}}^{\{\boldsymbol{p}\}^{\prime}} \boldsymbol{\operatorname { l n }} \emptyset_{M \boldsymbol{M o z}, \boldsymbol{n}}+\hat{\theta}_{n t}^{\{p\}}\right)
$$

where $\widehat{\alpha}^{\{p\}}, \widehat{\boldsymbol{\beta}}^{\{\boldsymbol{p}\}^{\prime}}$, and $\hat{\theta}_{n t}^{\{p\}}$ are respectively the estimates of $\alpha^{\{p\}}, \boldsymbol{\beta}^{\{\boldsymbol{p}\}}$, and $\theta_{n t}^{\{p\}}$ from the PPML regression with exporter-year and importer-year fixed effects. Notice that while we apply exporteryear fixed effects to obtain consistent parameter estimates when calibrating the model, we leave them out when predicting potential trade flows in Equation 16. We do so to avoid a situation in which Mozambique's current (in)ability to export certain target products influences our judgement

\footnotetext{
${ }^{17}$ Except the negative sign on common language under the naïve PPML model, all coefficients on the distance variables are as expected across all specifications. A comparison of the average point estimates on the distance variables and their average standard errors (both robust and clustered at the exporter-importer level) reveal that most distance coefficients are also significant at the 5 per cent level, on average, across all specifications. The coefficients of the additional controls in the naïve gravity equations are also broadly in line with our predictions, although some of them are insignificant on average. Taking point of departure in the naïve PPML estimation with cluster-robust standard errors, it seems that exporter's and importer's GDP per capita, remoteness, and status as landlocked do not have a significant effect on their bilateral trade in our target products.

${ }^{18}$ The formula used to calculate this effect is $\left(e^{\widehat{\beta}}-1\right) \times 100 . \hat{\beta}$ is the estimated coefficient.
} 
of these products' exportability in the future. We want to level the playing field, predicting which target products would generate the highest export revenue if Mozambique had an equal ability to produce each of them. In other words, we want to predict demand while taking the supply side as given. The exercise thereby gives an indication of which target product investments will generate the highest return in terms of export revenue.

The predicted values of $\widehat{T}_{M o z, n t}^{\{p\}}$ enable us to rank products in accordance with their potential to generate export revenue and countries for their potential as market destinations for the target products. First, we create a market export potential (MEP) variable, which captures the total estimated export value of all target products from Mozambique to each country $n$ over an eight year time period (2011-18):

$$
M E P_{n}=\sum_{p, t} \hat{T}_{M o z, n t}^{\{p\}}
$$

$M E P_{n}$ is a measure of the potential total trade in all target products between Mozambique and each country in the world. This allows us to evaluate which country is likely to be the biggest importer of Mozambique's target products. Cross-country variation in $M E P_{n}$ comes from variation in importer characteristics, such as import demand (captured by importer-year fixed effects), and different dyadic distances between Mozambique and each country (captured by $\emptyset_{\mathbf{n i}}$ ).

Second, we create a product export potential (PEP) variable by estimating the total predicted export value for each product over the same time period:

$$
P E P_{p}=\sum_{n, t} \widehat{T}_{M o z, n t}^{\{p\}}
$$

$P E P_{p}$ denotes the potential total trade in each target product between Mozambique and all countries of the world. Because we run Equation 16 separately for each target product, we obtain product-specific slope and fixed effect estimates, ensuring cross-product variation in $P E I_{p}$. Intuitively, the variation comes from different world import volumes across products (captured by product-specific intercepts and sums of importer-year fixed effects) and different effects of distance-variables on product-specific trade. For instance, some target products may have a high transportation cost and will be difficult for Mozambique to export (captured by the coefficient on physical distance). Other products may carry a certain cultural value, making it easier for Mozambique to export these products to former colonial powers or countries speaking Portuguese (captured by the coefficients on the similar-language dummy and the colonial-power dummy).

\subsection{Export potential}

\section{Product export potential}

Figure 12a displays the PEP for Mozambique's target products summed over product section and strategy. Values are reported as a percentage of total estimated exports of all target products. The figure provides a projected export revenue distribution over product sections if Mozambique were to export all target products. Not surprisingly, the export potential varies between product sections because the number of target products identified in each section varies. Therefore, Figure 12b displays the distribution of PEP averaged over the number of products within each section (and strategy) in order to give an idea of differences in per-product export potential. To ease interpretation, average PEP values are normalized so to that the highest (when considering both strategies 
combined) take the value 1 , whereas the lowest take the value 0 . Figures $\mathrm{A} 1-\mathrm{A} 3$ in the appendix show that the results from Figure 12 (based on the PPML model with fixed effects) are highly dependent on which of the four regression models from Table 4 is used to calculate PEP scores.

Figure 12 highlights important similarities and differences between the Industrial Policy and Strategy's selection of priority sectors (partly based on their export potential) and the export revenue projections from the gravity model. First, the gravity estimates show that the current prioritization of production in metals, minerals, paper goods, and agriculture (foodstuffs, live animals, vegetables, and animal hides) is well aligned with an ambition to increase export revenue. Target products within these sectors have high revenue potential in absolute terms. Of these product sections, minerals, animal hides, foodstuffs, and metals have the highest per-product PEP. This consolidates our finding from the supply-side analysis: there are important synergies between the structural transformation potential of these sectors and their export potential. These sectors should remain a focus for industrial policy in Mozambique. Second, the list of priority sectors appears to omit two important export drivers: machinery and electronics, and vehicles and transport equipment. The gravity model projects these product sections to account for nearly 60 per cent of total estimated exports from target products even though they 'only' account for 24 of 84 target products. Both product sections are also projected to deliver some of the highest revenues per exported product. When combining these results with those from the supply-side analysis, the omission of these two sectors from the list of priority sectors in Mozambique seems misguided. Products within these sectors have high potential to drive both structural transformation and export revenue. Finally, and at the other end of the spectrum, only two target products were identified in textiles and wood products, and these products also have very low export potential — in both absolute and per-product terms. It thus seems that clothing, textiles, and footwear, along with wood and furniture processing, are the least important of Mozambique's seven priority sectors.

Figure 12: Total PEP and average PEP by product section and strategy (PPML fixed effects)
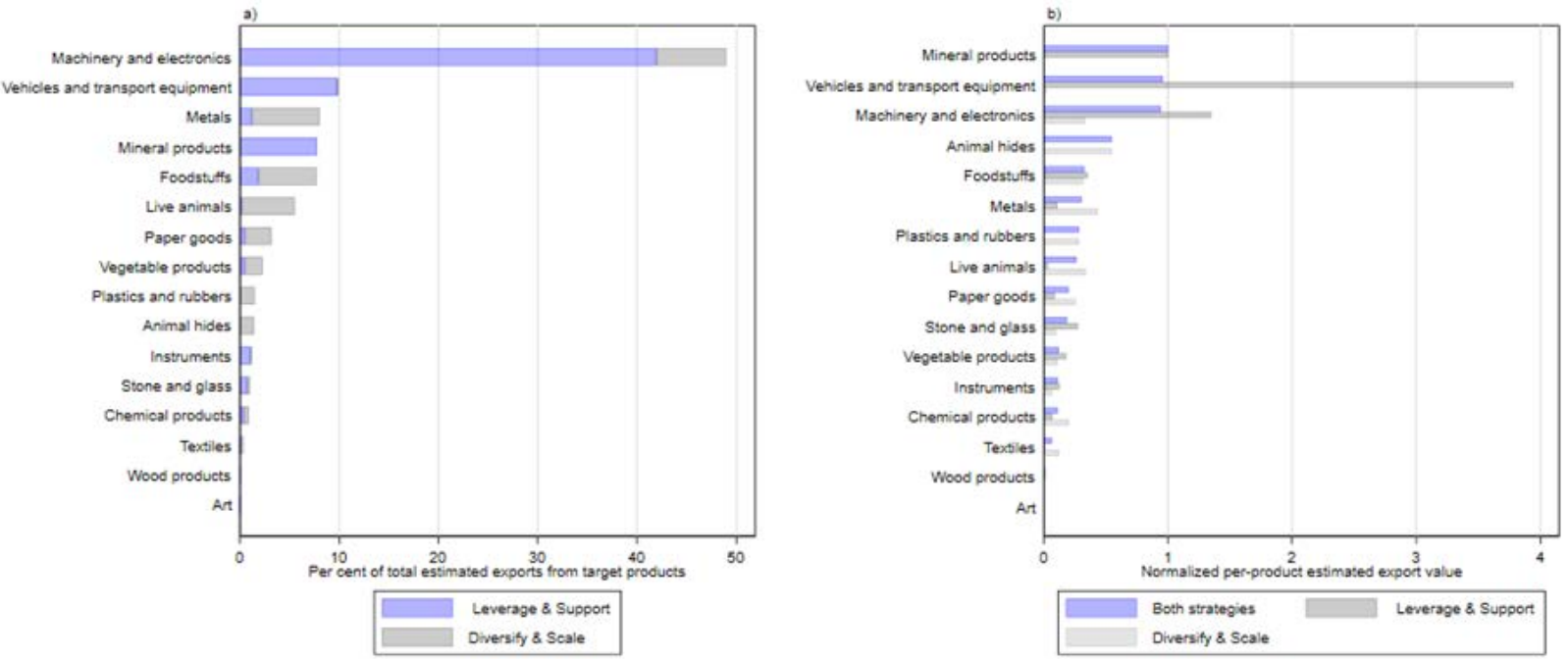

Note: PEP estimates are based on the PPML regression with exporter-year and importer-year fixed effects (Column 4, Table 4).

Source: authors' calculations based on trade data from Growth Lab (2019).

We note that that the export potential is highest in target products that Mozambique already exports (identified by the Leverage \& Support strategy) in machinery and electronics, vehicles and transport equipment, and mineral products. From a revenue perspective, Mozambique should take 
advantage of the favourable demand exposure to boost the intensive margin of trade in these product sections. In product sections where the opposite is true (for example metals, animal hides, live animals, paper goods, chemical products, and plastic and rubbers), the export potential is highest in the products that Mozambique is not yet exporting. Here, policies aiming to boost export revenues may be most effective when focusing on the extensive margin.

\section{Market export potential}

The implementation of effective export promotion policies dictates an identification of highpotential export markets. Figure 13 shows which countries the gravity model predicts as important export destinations for Mozambique's target products. The graph shows which countries are currently importing most of Mozambique's exports, and the degree to which these destinations are predicted to be important importers of Mozambique's target products. The vertical line on the graph represents each countries' import share of Mozambique's total exports in 2018. The share in imports is reported in logarithmic form $\left(\log _{10}\right)$, meaning that -1 represents 10 per cent, -2 represents 1 per cent, and so forth. The horizontal axis reports Mozambique's projected export of all target products to each import market as a share of its total projected export across all target products and markets. It is calculated as the $\log _{10}$ of each importer's MEP value divided by the sum of all countries' MEP values from 2011 to 2018.

Figure 13: Import share of Mozambique's 2018 exports versus import share of Mozambique's estimated target product exports over eight years (PPML fixed effects)

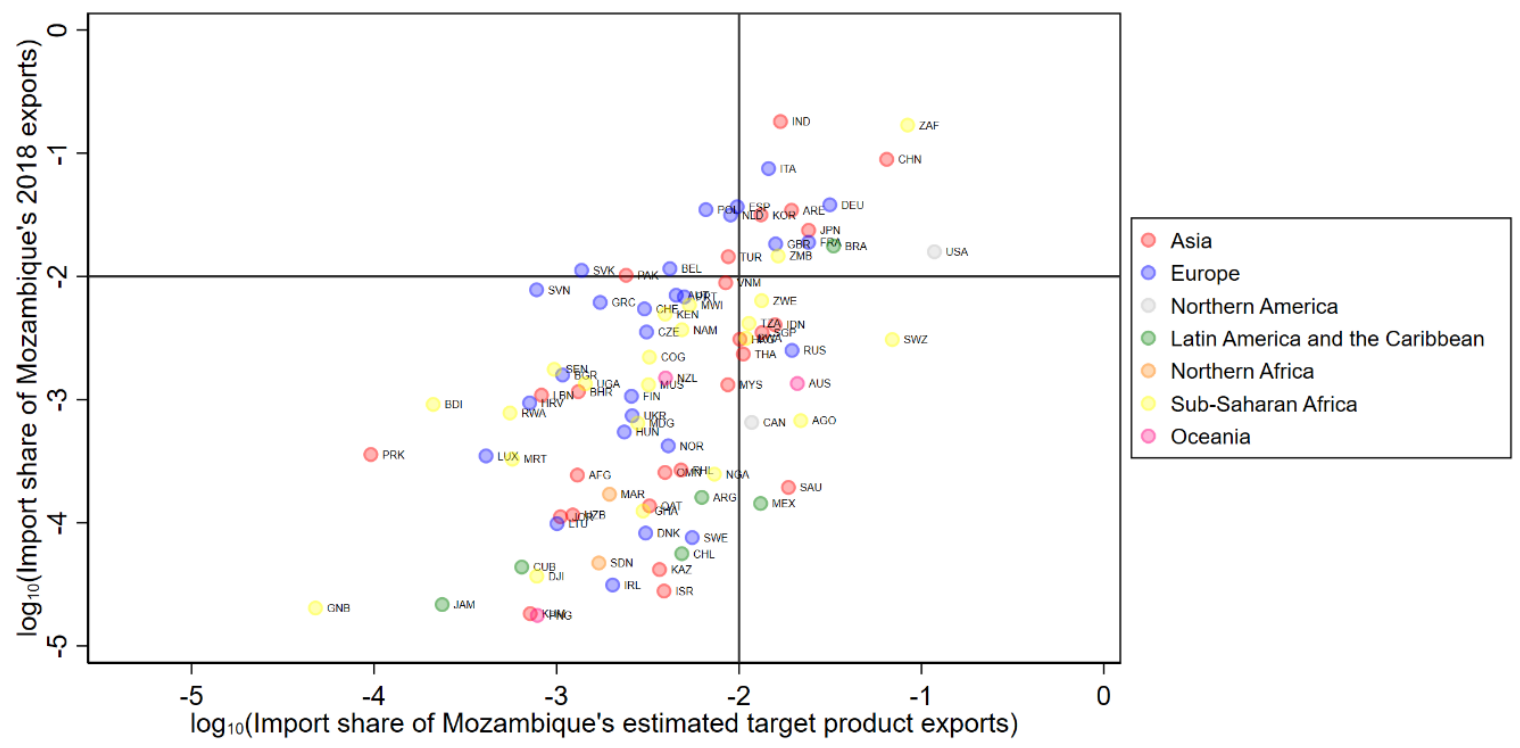

Note: MEP estimates are based on the PPML regression with exporter-year and importer-year fixed effects (Column 4, Table 4).

Source: authors' calculations based on trade data from Growth Lab (2019).

One immediate conclusion is evident from Figure 13: there is a positive (log-)linear relationship between Mozambique's current volume of exports to other countries and these countries' predicted import share of Mozambique's target product exports. This is encouraging because it indicates that Mozambique's current trade partners can drive target product export growth. In other words, the result indicates that Mozambique does not need to penetrate many new markets or change the structure of its market portfolio significantly in order to export the identified target products. 
Yet there is still some room to attune Mozambique's portfolio of trade partners to accommodate export growth in target products. Countries located in the bottom-left quadrant of Figure 13 are low-potential export markets. These are countries with which Mozambique currently trades little, and nor are they predicted to import Mozambique's target products in high volumes in the future. Many Sub-Saharan African and Latin American countries are located in this quadrant. Notably, it also includes countries such as Portugal and Vietnam. The countries in the upper-left quadrant are hard-to-exploit export markets. Countries located here are important for Mozambique's current trade, but they are predicted to be unimportant importers of its target products in the future. The quadrant includes Turkey, Pakistan, the Netherlands, Belgium, Spain, Poland, and Slovakia. Countries located in the top-right quadrant constitute high-potential markets. These countries are important current markets for Mozambique and they are estimated to import the country's target products in great volumes in the future. We note that the countries located here are large European and Asian economies, Brazil, the USA, Zambia, and South Africa. Finally, the bottom-right quadrant is home to high-opportunity markets. Mozambique does not currently trade much with these countries, but they have a high projected demand for its target products. This group of countries includes a substantial number of Mozambique's neighbouring countries (Eswatini, Zimbabwe, and Tanzania) and other Southern African countries (Angola and Botswana). There is thus great untapped potential for Mozambique in trading with its neighbours and other Southern African countries in new and complex products. Trade policy aimed at expanding the scope of intraregional trade agreements such as SADC may be a way for Mozambique to realize this potential. Hong Kong, Singapore, Indonesia, Thailand, and Saudi Arabia constitute high-opportunity Asian markets. Russia, Australia, Canada, and Mexico are also identified as promising markets for Mozambique's target products.

Figures A4-A6 in the appendix replicate Figure 13 based on predicted exports from the naive PPML and OLS regressions and the fixed effect OLS regression. The tables show that a correct model specification is crucial for drawing valid conclusions. For example, the higher absolute values of the coefficients on distance and contiguity in the OLS regressions mean that these models overestimate the potential for Mozambique to export the target products to its neighbours. The naïve PPML model also overstates the border effect and assigns inflated MEP values to Mozambique's neighbours.

\section{$4 \quad$ Discussion and conclusion}

Economic growth entails a structural transformation process whereby productive resources are moved from low-complexity to high-complexity activities. The discovery of a heterogeneous product space has highlighted that externalities and path dependencies are inherent parts of this process (Hausmann and Klinger 2007; Hidalgo et al. 2007). The question of whether and how governments can guide this process through industrial policy has therefore gained considerable attention in many developing countries (Hausmann and Chauvin 2015; Hausmann and Klinger 2006a; Hausmann et al., 2014, 2016). This question is particularly relevant for Mozambique, whose export structure is undiversified and unsophisticated. To guide industrial policy, we have identified a set of target products that are complex, rely on productive capabilities complementary to the production of many other products, and are relatively close to Mozambique's current know-how. Acknowledging that export revenue constitutes a significant policy objective in Mozambique, a demand-side analysis has ranked target products and export markets in accordance with their predicted export potential. The main conclusions can be summarized in two steps.

First, Mozambique's current industrial policy is, broadly speaking, consistent with a focus on structural transformation and export promotion. The broad sectoral focus is consistent with our 
findings in this paper, with the general concern that Mozambique is too reliant on exports from a few extractive industries (Cruz and Mafambissa 2016; Dietsche and Esteves 2018), and with the stylized empirical fact that diversification is good for growth (Cristelli et al. 2013, 2017; Hausmann et al. 2013). That said, the priority given to agriculture, agro-industry, and metal products seems especially important when the potential for structural transformation and export growth are considered simultaneously. Our analysis also highlights unexploited opportunities especially in machinery and electronics and vehicles and transport equipment. Notably, firms in Mozambique already export many of the products identified in these sectors, although in relatively small volumes. Second, gravity model estimates show that Mozambique's largest current trade partners are those predicted to import the lion's share of its target products in the future. Mozambique's current pattern of trade can, however, still be attuned to accommodate export growth in target products. As an example, we find potential for Mozambique to export target products to its neighbours and other Southern African countries, indicating the importance of a continued deepening of regional trade agreements such as SADC.

The results presented here have direct implications for industrial policy. It is therefore pertinent to stress what the core principles of such policies should (and should not) be. First, Mozambique should invest in capabilities, not products. This argument is about first principles. From the perspective of economic complexity, products are only interesting because they are signals about productive know-how. The only reason behind the product-focused analysis adopted in this paper is the practical impossibility of identifying the exact capabilities related to all 1,200-plus products of the world. Thus, the sectors identified in this paper should primarily be seen as a suggested roadmap to guide the search for the capabilities necessary for Mozambique to diversify and upgrade its economy. Only if the primary objective is to grow export revenue may an explicit focus on specific products be justifiable. Second, this paper is not a call for 'picking winners'. The analysis has shown that opportunities exist in a wide variety of sectors. By picking some sectors above others, the government may effectively condemn potential successes in non-prioritized sectors. A first principle in industrial policy should therefore be to make any interventions as broadly applicable and sector-neutral as possible (Hausmann and Klinger 2006a). When the government is doomed to choose, however, the analyses presented here have shown a structured and somewhat neutral way of prioritizing. Third, economic theory tells us that government intervention is only welfareenhancing in the presence of market failures, such as externalities in product diversification. Industrial policy should only do what the market cannot accomplish on its own, and interventions should be guided by market signals to the extent possible. This principle has been the intention behind the Leverage \& Support strategy developed in this paper.

The distinction between the low-hanging fruits and strategic bets components of our strategy implies a sequential implementation of industrial policy. While the sectors identified by the strategic bets component offer greater potential for complexity gains, they may be difficult to pursue in the short run. The current level of human capital and technological capacity in Mozambique is low and likely inadequate to build comparative advantages in these sectors in the immediate future. Moving into these industries is a costly and long-term process that will likely require investment in infrastructure, human capital, sophisticated technologies, inflow of FDI, and so on. In contrast, the low-hanging fruits component lies closer to the productive know-how Mozambique already possesses and allows for a more intense application of the technologies and skills already present in the economy. A focus on low-hanging fruits may therefore be the most feasible strategy in the short run.

Furthermore, the policy implications of this paper should be interpreted in relation to the limitations of the method applied. Compared with the objectives listed in the Industrial Policy and Strategy 2016-2025, our study has a narrower focus on promoting economic complexity and export revenue. This has consequences for the industries we identify as important. For instance, 
we do not focus on the labour intensity of products and sectors in this paper, even though employment generation is a stated objective in Mozambique's current prioritization of industries. In related work, we explore this aspect in the context of Tanzania and find an inverse relationship between PCI and labour intensities in products (Estmann et al. 2020). This implies a trade-off between job creation and complexity, and it suggests that the low-hanging fruit component of the two strategies proposed in this paper may strike the best balance between these objectives because it assigns a lower weight to PCI. Another limitation of the complexity approach relates to data availability. International trade data do not include granular information on services, and they obviously miss data on any non-tradable sectors. As a consequence, we are unable to evaluate claims from other studies arguing that industries without smokestacks ${ }^{19}$ constitute an important piece in Mozambique's diversification puzzle (Cruz and Mafambissa 2016) and that the construction sector is important for the domestic market (Cruz et al. 2018). Industrial policy should ideally consider all relevant sectors and objectives when prioritizing.

Despite these shortcomings, this paper make two contributions to the literature. We extend the methodology of supply-side-focused economic complexity analysis applied in a number of studies to guide industrial policy in developing countries (Ayres and Freire 2014; Hausmann and Chauvin 2015; Hausmann and Klinger 2006a; Hausmann et al. 2014, 2016, 2017; Hidalgo 2011) with a structured demand-side analysis, ranking products in accordance with their revenue-generating trade potential. Most other studies do not consider demand-side factors at all, and none use gravity models to map the export potential of products and markets. The analysis has highlighted significant synergies between the structural transformation potential of different sectors and their potential for exports. Additionally, this paper constitutes, to the best of our knowledge, the first comprehensive study on economic complexity and structural transformation in Mozambique. The complexity framework offers a different perspective to the CGE models that have traditionally been used to evaluate the attractiveness of different sectors in the country (Arndt et al. 2010; Hartley et al. 2019; Jensen and Tarp 2004). These models enable a detailed evaluation of economic aggregates and the distributional consequences of one specific shock or a policy intervention in one specific sector. Such detailed response analysis is impossible with the economic complexity analysis conducted in this paper. Rather, its strength lies in its ability to evaluate the attractiveness of all sectors/products simultaneously. The analysis is data-driven: we make no judgement calls on which sector to focus on a priori. This can lead to new and surprising conclusions, like the one found in this paper on Mozambique's opportunities in machinery production. Another strength lies in the ability to provide policy recommendations at the product level by explicitly modelling the externalities associated with each product. A policy-relevant avenue of further research would be to combine these two models, using the economic complexity framework to identify the most promising sectors and a CGE model to evaluate the economic consequences of targeting that sector with industrial policy.

\section{References}

Albeaik, S., M. Kaltenberg, M. Alsaleh, and C.A. Hidalgo (2017). 'Improving the Economic Complexity Index’. ArXiv. https://arxiv.org/abs/1707.05826

\footnotetext{
${ }^{19}$ Industries without smokestacks are industries sharing the characteristics of the manufacturing sector. Examples include sectors such as food processing and horticulture, but also tourism, ICT, and other services.
} 
Arndt, C., H.T. Jensen, and F. Tarp (2000). 'Stabilization and Structural Adjustment in Mozambique: An Appraisal'. Journal of International Development, 12 (3): 299-323. https://doi.org/10.1002/(SICI)10991328(200004)12:3<299::AID-JID653>3.0.CO;2-N

Arndt, C., R. Benfica, F. Tarp, J. Thurlow, and R. Uaiene (2010). 'Biofuels, Poverty, and Growth: A Computable General Equilibrium Analysis of Mozambique'. Environment and Development Economics, 15(1): 81-105. https://doi.org/10.1017/S1355770X09990027

Atlas (2019). 'Atlas of Economic Complexity by the Growth Lab at Harvard University'. Available at: http:/ /atlas.cid.harvard.edu (accessed 8 December 2019).

Ayres, S., and C. Freire (2014). 'In Which Industries to Invest? Aligning Market and Development Incentives in Myanmar'. Southeast Asian Economies, 31(3): 395. https://doi.org/10.1355/ae31-3d

Bajgar, M., and B. Javorcik (2020). 'Climbing the Rungs of the Quality Ladder: FDI and Domestic Exporters in Romania'. The Economic Journal, 130(628): 937-55. https://doi.org/10.1093/ej/ueaa003

Bernard, A.B., S.J. Redding, and P.K. Schott (2010). 'Multiple-Product Firms and Product Switching'. American Economic Review, 100(1):70-97. https://doi.org/10.1257/aer.100.1.70

CEPII (2015). 'Geography: Gravity'. Available at: http://www.cepii.fr/CEPII/en/bdd_modele/ download.asp?id=8 (accessed August 2020).

Cristelli, M., A. Gabrielli, A. Tacchella, G. Caldarelli, and L. Pietronero (2013). 'Measuring the Intangibles: A Metrics for the Economic Complexity of Countries and Products'. PLOS ONE, 8(8): e70726. https://doi.org/10.1371/journal.pone.0070726

Cristelli, M., A. Tacchella, M. Cader, K. Roster, and L. Pietronero (2017). 'On the Predictability of Growth'. Policy Research Working Paper 8117. Washington, DC: World Bank. https://doi.org/10.1596/18139450-8117

Cruz, A.S., and F.J. Mafambissa (2016). 'Industries without Smokestacks: Mozambique Country Case Study'. WIDER Working Paper 2016/158. Helsinki: UNU-WIDER. https:/ / doi.org/10.35188/UNU-WIDER/2016/202-1

Cruz, A.S., F. Fernandes, F.J. Mafambissa, and F. Pereira (2018). 'The Construction Sector in Mozambique: An Overview'. WIDER Working Paper 2018/117. Helsinki: UNU-WIDER. https://doi.org/10.35188/UNU-WIDER/2018/559-6

Dietsche, E., and A.M. Esteves (2018). 'What Are the Prospects for Mozambique to Diversify Its Economy on the Back of “Local Content”?' WIDER Working Paper 2018/113. Helsinki: UNU-WIDER. https://doi.org/10.35188/UNU-WIDER/2018/555-8

Eck, K., and S. Huber (2016). 'Product Sophistication and Spillovers from Foreign Direct Investment'. Canadian Journal of Economics/Revue canadienne d'économique, 49(4): 1658-84. https://doi.org/10.1111/caje.12247

Estmann, C., B.B. Sørensen, B. Ndulu, and J. Rand (2020). 'Merchandise Export Diversification Strategy for Tanzania: Promoting Inclusive Growth, Economic Complexity and Structural Change'. DERG Working Paper. Copenhagen: DERG, University of Copenhagen.

Fally, T (2015). 'Structural Gravity and Fixed Effects'. Journal of International Economics, 97(1): 76-85. https://doi.org/10.1016/j.jinteco.2015.05.005

Goldberg, P.K., A.K. Khandelwal, N. Pavcnik, and P. Topalova (2010). 'Multiproduct Firms and Product Turnover in the Developing World: Evidence Form India'. The Review of Economics and Statistics, 92(4): 1042-49. https://doi.org/10.1162/REST_a_00047

GoM (Government of Mozambique) (2014a). Estratégia Nacional de Desenvolvimento 2015-2035. Maputo: República de Moçambique.

GoM (2014b). Politica e Estratégia Industrial 2016-2025. Maputo: Ministério da Indústria e Comércio, República de Moçambique.

Growth Lab 2019. 'International Trade Data (HS, 92)'. https://doi.org/10.7910/DVN/H8SFD2 
Growth Lab 2020. 'The Atlas of Economic Complexity’. Available at: http://www.atlas.cid.harvard.edu (accessed 1 May 2020).

Hanson, G.H (2005). 'Market Potential, Increasing Returns and Geographic Concentration'. Journal of International Economics, 67(1): 1-24. https://doi.org/10.1016/j.jinteco.2004.09.008

Hartley, F., D. van Seventer, E. Tostão, and C. Arndt (2019). 'Economic Impacts of Developing a Biofuel Industry in Mozambique'. Development Southern Africa, 36(2): 233-49. https://doi.org/10.1080/0376835X.2018.1548962

Hausmann, R., and J. Chauvin (2015). 'Moving to the Adjacent Possible: Discovering Paths for Export Diversification in Rwanda'. CID Working Paper 294. Cambridge, MA: Centre for International Development (CID), Harvard University.

Hausmann, R., and C.A. Hidalgo (2013). 'How Will the Netherlands Earn Its Income 20 Years From Now? A Growth Ventures Analysis for the Netherlands Scientific Council for Government Policy (WRR)'. Webpublication 74. The Hague: Netherlands Scientific Council for Government Policy.

Hausmann, R., and B. Klinger (2006a). 'South Africa's Export Predicament'. CID Working Paper 129. Cambridge, MA: CID, Harvard University. https://doi.org/10.2139/ssm.939650

Hausmann, R., and B. Klinger (2006b). 'Structural Transformation and Patterns of Comparative Advantage in the Product Space'. CID Working Paper 128. Cambridge, MA: CID, Harvard University. https://doi.org/10.2139/ssm.939646

Hausmann, R., and B. Klinger (2007). 'The Structure of the Product Space and the Evolution of Comparative Advantage'. CID Working Paper 146. Cambridge, MA: CID, Harvard University.

Hausmann, R., J.R. Morales, and M.A. Santos (2016). 'Panama beyond the Canal: Using Technological Proximities to Identify Opportunities for Productive Diversification'. CID Working Paper 324. Cambridge, MA: CID, Harvard University. https://doi.org/10.2139/ssrn.2880643

Hausmann, R., M.A. Santos, and J.J. Obach (2017). 'Appraising the Economic Potential of Panama'. CID Working Paper 334. Cambridge, MA: CID, Harvard University.

Hausmann, R., B. Cunningham, J.M. Matovu, R. Osire, and K. Wyett (2014). 'How Should Uganda Grow?' CID Working Paper 275. Cambridge, MA: CID, Harvard University.

Hausmann, R., P. Goldstein, A. Grisanti, T. O’Brien, J. Tapia, and M. Angel Santos (2019). 'A Roadmap for Investment Promotion and Export Diversification: The Case of Jordan’. CID Working Paper 374. Cambridge, MA: CID, Harvard University.

Hausmann, R., C.A. Hidalgo, S. Bustos, M. Coscia, A. Simoes, and M.A. Yildrim (eds) (2013). The Atlas of Economic Complexity: Mapping Paths to Prosperity. Cambridge, MA: The MIT Press. https://doi.org/10.7551/mitpress/9647.001.0001

Head, K., and T. Mayer (2004). 'Market Potential and the Location of Japanese Investment in the European Union'. Review of Economics and Statistics, 86(4): 959-72. https://doi.org/10.1162/0034653043125257

Head, K., and T. Mayer (2014). 'Gravity Equations: Workhorse, Toolkit, and Cookbook'. In G. Gopinath, E. Helpman, and K. Rogoff (eds), Handbook of International Economics, vol. 4. Oxford and Amsterdam: Elsevier North-Holland. https:// doi.org/10.1016/B978-0-444-54314-1.00003-3

Hidalgo, C.A (2011). Discovering Southern and East Africa's Industrial Opportunities. Washington, DC: The German Marshall Fund of the United States.

Hidalgo, C.A, and R. Hausmann (2009). 'The Building Blocks of Economic Complexity'. Proceedings of the National Academy of Sciences, 106(26): 10570-75. https://doi.org/10.1073/pnas.0900943106

Hidalgo, C.A., B. Klinger, A.L. Barabasi, and R. Hausmann (2007). ${ }^{\circ}$ The Product Space Conditions the Development of Nations'. Science, 317(5837): 482-87. https://doi.org/10.1126/science.1144581

IMF (2016). 'Republic of Mozambique: Selected Issues: Macroeconomic and Fiscal Implications of Natural Gas Project'. Country Report 16/10. Washington, DC: IMF. https://doi.org/10.5089/9781513539065.002 
Javorcik, B.S (2004). 'Does Foreign Direct Investment Increase the Productivity of Domestic Firms? In Search of Spillovers Through Backward Linkages'. The American Economic Review, 94(3): 71. https://doi.org/10.1257/0002828041464605

Javorcik, B.S., A. Lo Turco, and D. Maggioni (2018). New and Improved: Does FDI Boost Production Complexity in Host Countries?' The Economic Journal, 128(614): 2507-37. https://doi.org/10.1111/ecoj.12530

Jensen, H.T., and F. Tarp (2004). 'On the Choice of Appropriate Development Strategy: Insights Gained from CGE Modelling of the Mozambican Economy'. Journal of African Economies, 13(3): 446-78. https://doi.org/10.1093/jae/ejh026

Jones, S., and F. Tarp (2015). 'Understanding Mozambique's Growth Experience through an Employment Lens’. WIDER Working Paper 2015/109. Helsinki: UNU-WIDER. https:// doi.org/10.35188/UNUWIDER/2015/998-5

Mayer, T., and S. Zignago (2011). 'Notes on CEPII's Distances Measures: The GeoDist Database'. Paris: CEPII. https://doi.org/10.2139/ssrn.1994531

Mondlane, S., and D. van Seventer (2019). 'Agricultural Development, Trade, and Income Distribution: A 2015 Social Accounting Matrix Multiplier Decomposition Approach for Mozambique’. WIDER Working Paper 2019/77. Helsinki: UNU-WIDER. https://doi.org/10.35188/UNUWIDER/2019/711-8

Moran, T (2007). 'How to Investigate the Impact of Foreign Direct Investment on Development, and Use the Results to Guide Policy'. Brookings Trade Forum 2007. Washington, DC: Brookings Institution Press.

Newman, C., J. Rand, and F. Tarp (2013). 'Industry Switching in Developing Countries'. The World Bank Economic Review, 27(2): 357-88. https:/ / doi.org/10.1093/wber/lhs030

Newman, C., J. Rand, T. Talbot, and F. Tarp (2015). 'Technology Transfers, Foreign Investment and Productivity Spillovers'. European Economic Review, 76: 168-87. https://doi.org/10.1016/j.euroecorev.2015.02.005

Rand, J., and F. Tarp (2002). 'Business Cycles in Developing Countries: Are They Different?' World Development, 30(12): 2071-88. https://doi.org/10.1016/S0305-750X(02)00124-9

Redding, S., and A.J. Venables (2004). 'Economic Geography and International Inequality'. Journal of International Economics, 62(1): 53-82. https://doi.org/10.1016/j.jinteco.2003.07.001

Roe, A.R (2018). 'Extractive Industries and Development: Lessons from International Experience for Mozambique'. WIDER Working Paper 2018/56. Helsinki: UNU-WIDER. https://doi.org/10.35188/UNU-WIDER/2018/498-8

Saltarelli, F., V. Cimini, A. Tacchella, A. Zaccaria, and M. Cristelli (2020). 'Is Export a Probe for Domestic Production?’ Frontiers in Physics, 26 June. https://doi.org/10.3389/fphy.2020.00180

Santos Silva, J.M.C., and S. Tenreyro (2006). 'The Log of Gravity.' The Review of Economics and Statistics, 88(4): 641-58. https://doi.org/10.1162/rest.88.4.641

Santos Silva, J.M.C., and S. Tenreyro (2011). 'Further Simulation Evidence on the Performance of the Poisson Pseudo-Maximum Likelihood Estimator'. Economics Letters, 112(2): 220-22. https://doi.org/10.1016/j.econlet.2011.05.008

Sørensen, B.B (2020). 'Turnin’ It up a Notch: How Spillovers from Foreign Direct Investment Boost the Complexity of South Africa's Exports'. WIDER Working Paper 2020/3. Helsinki: UNU-WIDER. https://doi.org/10.35188/UNU-WIDER/2020/760-6

Sutton, J., A. Jeque Pimpão, F. Simione, and S. Zita (2014). An Enterprise Map of Mozambique. London: International Growth Centre.

Tacchella, A., M. Cristelli, G. Caldarelli, A. Gabrielli, and L. Pietronero (2012). 'A New Metrics for Countries' Fitness and Products' Complexity'. Scientific Reports, 2: article 723. https://doi.org/10.1038/srep00723 
Toews, G., and P.-L. Vezina (2018). 'Resource Discoveries and FDI Bonanzas: An Illustration from Mozambique'. OxCarre Working Paper 199. Oxford: Oxford Centre for the Analysis of Resource Rich Economies, University of Oxford.

World Bank (2020). 'World Development Indicators'. Available at: https://datacatalog.worldbank.org/dataset/world-development-indicators (accessed July 2020).

WTO (2020). 'Regional Trade Agreements Database'. Available at: https://rtais.wto.org/UI/PublicMaintainRTAHome.aspx (accessed August 2020). 
Appendix

Table A1: Target products from Leverage \& Support strategy, low-hanging fruits component

\begin{tabular}{|c|c|c|c|c|c|c|c|c|}
\hline $\begin{array}{l}\text { HS } \\
\text { code }\end{array}$ & Description & $\begin{array}{l}\text { Product } \\
\text { group }\end{array}$ & Rank & $\mathrm{RCA}$ & Density & $\mathrm{PCl}$ & OGI & $\begin{array}{r}\text { Weighted } \\
\text { score }\end{array}$ \\
\hline 8479 & Machines n.e.c. & $\begin{array}{l}\text { Machinery and } \\
\text { electronics }\end{array}$ & 1 & 0.09 & -1.53 & 2.20 & 2.31 & 0.55 \\
\hline 8431 & $\begin{array}{l}\text { Parts for use with hoists } \\
\text { and excavation machinery }\end{array}$ & $\begin{array}{l}\text { Machinery and } \\
\text { electronics }\end{array}$ & 2 & 0.06 & -0.24 & 1.12 & 1.20 & 0.53 \\
\hline 8485 & $\begin{array}{l}\text { Machinery parts, not } \\
\text { containing electrical } \\
\text { features, n.e.c. }\end{array}$ & $\begin{array}{l}\text { Machinery and } \\
\text { electronics }\end{array}$ & 3 & 0.12 & -0.68 & 1.27 & 1.44 & 0.44 \\
\hline 8412 & Other engines and motors & $\begin{array}{l}\text { Machinery and } \\
\text { electronics }\end{array}$ & 4 & 0.04 & -0.79 & 1.27 & 1.52 & 0.42 \\
\hline 9024 & $\begin{array}{l}\text { Machines for testing the } \\
\text { mechanical properties of } \\
\text { materials }\end{array}$ & Instruments & 5 & 0.04 & -1.16 & 1.55 & 1.62 & 0.35 \\
\hline 8503 & $\begin{array}{l}\text { Parts for use with electric } \\
\text { generators }\end{array}$ & $\begin{array}{l}\text { Machinery and } \\
\text { electronics }\end{array}$ & 6 & 0.16 & -0.43 & 0.91 & 0.98 & 0.33 \\
\hline 2501 & Salt & $\begin{array}{l}\text { Mineral } \\
\text { products }\end{array}$ & 7 & 0.01 & 2.41 & -1.10 & -1.62 & 0.32 \\
\hline 4415 & Packing boxes & Wood products & 8 & 0.13 & 0.61 & 0.27 & -0.06 & 0.32 \\
\hline 3602 & $\begin{array}{l}\text { Prepared explosives, } \\
\text { except gunpowder }\end{array}$ & $\begin{array}{l}\text { Chemical } \\
\text { products }\end{array}$ & 9 & 0.00 & 2.09 & -1.05 & -1.25 & 0.30 \\
\hline 5602 & Felt & Textiles & 10 & 0.20 & -0.46 & 0.81 & 1.02 & 0.30 \\
\hline 8474 & $\begin{array}{l}\text { Machinery for working } \\
\text { minerals }\end{array}$ & $\begin{array}{l}\text { Machinery and } \\
\text { electronics }\end{array}$ & 11 & 0.82 & -0.39 & 0.76 & 0.94 & 0.29 \\
\hline 2523 & Cements & $\begin{array}{l}\text { Mineral } \\
\text { products }\end{array}$ & 12 & 0.75 & 2.72 & -1.43 & -1.94 & 0.28 \\
\hline 7602 & Waste or scrap, aluminium & Metals & 13 & 0.90 & 1.88 & -0.98 & -1.10 & 0.27 \\
\hline 7302 & $\begin{array}{l}\text { Railway construction } \\
\text { material of iron or steel }\end{array}$ & Metals & 14 & 0.03 & -0.10 & 0.53 & 0.61 & 0.27 \\
\hline 4404 & $\begin{array}{l}\text { Strips and other pieces of } \\
\text { wood }\end{array}$ & Wood products & 15 & 0.23 & 1.01 & -0.10 & -0.54 & 0.27 \\
\hline 0804 & $\begin{array}{l}\text { Avocados, pineapples, } \\
\text { mangos, etc. }\end{array}$ & $\begin{array}{l}\text { Vegetable } \\
\text { products }\end{array}$ & 16 & 0.28 & 3.15 & -1.93 & -2.24 & 0.26 \\
\hline 8429 & $\begin{array}{l}\text { Self-propelled bulldozers, } \\
\text { excavators and road } \\
\text { rollers }\end{array}$ & $\begin{array}{l}\text { Machinery and } \\
\text { electronics }\end{array}$ & 17 & 0.49 & -0.25 & 0.43 & 0.90 & 0.26 \\
\hline 2306 & $\begin{array}{l}\text { Solid vegetable oil and fat } \\
\text { residues }\end{array}$ & Foodstuffs & 18 & 0.69 & 2.03 & -1.01 & -1.33 & 0.26 \\
\hline 8455 & Metal-rolling mills & $\begin{array}{l}\text { Machinery and } \\
\text { electronics }\end{array}$ & 19 & 0.00 & -0.82 & 1.06 & 1.19 & 0.26 \\
\hline 0511 & Animal products n.e.c. & Live animals & 20 & 0.42 & 1.75 & -0.82 & -1.10 & 0.25 \\
\hline 8535 & $\begin{array}{l}\text { Electrical apparatus for } \\
>1 \mathrm{k} \text { volts }\end{array}$ & $\begin{array}{l}\text { Machinery and } \\
\text { electronics }\end{array}$ & 21 & 0.14 & -0.65 & 0.91 & 1.05 & 0.25 \\
\hline 0106 & Other live animals & Live animals & 22 & 0.33 & 2.30 & -1.35 & -1.50 & 0.25 \\
\hline 8438 & $\begin{array}{l}\text { Machinery for the } \\
\text { industrial preparation of } \\
\text { food or drink }\end{array}$ & $\begin{array}{l}\text { Machinery and } \\
\text { electronics }\end{array}$ & 23 & 0.21 & -0.71 & 0.93 & 1.12 & 0.25 \\
\hline 2713 & Petroleum coke & $\begin{array}{l}\text { Mineral } \\
\text { products }\end{array}$ & 24 & 0.30 & 1.69 & -0.76 & -1.07 & 0.25 \\
\hline 2202 & $\begin{array}{l}\text { Waters, flavored or } \\
\text { sweetened }\end{array}$ & Foodstuffs & 25 & 0.35 & 1.24 & -0.35 & -0.75 & 0.25 \\
\hline
\end{tabular}

Note: density refers to the inverse of distance and is calculated as distance minus 1.

Source: authors' calculations based on trade data from Growth Lab (2019). 
Table A2: Target products from Leverage \& Support strategy, strategic bets component

\begin{tabular}{|c|c|c|c|c|c|c|c|c|}
\hline $\begin{array}{l}\text { HS } \\
\text { code }\end{array}$ & Description & $\begin{array}{l}\text { Product } \\
\text { group }\end{array}$ & Rank & RCA & Density & $\mathrm{PCl}$ & OGI & $\begin{array}{r}\text { Weighted } \\
\text { score }\end{array}$ \\
\hline 8479 & Machines n.e.c. & $\begin{array}{l}\text { Machinery and } \\
\text { electronics }\end{array}$ & 1 & 0.09 & -1.53 & 2.20 & 2.31 & 1.52 \\
\hline 9024 & $\begin{array}{l}\text { Machines for testing the } \\
\text { mechanical properties of } \\
\text { materials }\end{array}$ & Instruments & 2 & 0.04 & -1.16 & 1.55 & 1.62 & 1.05 \\
\hline 8412 & Other engines and motors & $\begin{array}{l}\text { Machinery and } \\
\text { electronics }\end{array}$ & 3 & 0.04 & -0.79 & 1.27 & 1.52 & 1.01 \\
\hline 8485 & $\begin{array}{l}\text { Machinery parts, not } \\
\text { containing electrical } \\
\text { features, n.e.c. }\end{array}$ & $\begin{array}{l}\text { Machinery and } \\
\text { electronics }\end{array}$ & 4 & 0.12 & -0.68 & 1.27 & 1.44 & 0.98 \\
\hline 8431 & $\begin{array}{l}\text { Parts for use with hoists } \\
\text { and excavation machinery }\end{array}$ & $\begin{array}{l}\text { Machinery and } \\
\text { electronics }\end{array}$ & 5 & 0.06 & -0.24 & 1.12 & 1.20 & 0.90 \\
\hline 8455 & Metal-rolling mills & $\begin{array}{l}\text { Machinery and } \\
\text { electronics }\end{array}$ & 6 & 0.00 & -0.82 & 1.06 & 1.19 & 0.76 \\
\hline 8438 & $\begin{array}{l}\text { Machinery for the } \\
\text { industrial preparation of } \\
\text { food or drink }\end{array}$ & $\begin{array}{l}\text { Machinery and } \\
\text { electronics }\end{array}$ & 7 & 0.21 & -0.71 & 0.93 & 1.12 & 0.72 \\
\hline 8503 & $\begin{array}{l}\text { Parts for use with electric } \\
\text { generators }\end{array}$ & $\begin{array}{l}\text { Machinery and } \\
\text { electronics }\end{array}$ & 8 & 0.16 & -0.43 & 0.91 & 0.98 & 0.68 \\
\hline 5602 & Felt & Textiles & 9 & 0.20 & -0.46 & 0.81 & 1.02 & 0.68 \\
\hline 8535 & $\begin{array}{l}\text { Electrical apparatus for } \\
>1 \mathrm{k} \text { volts }\end{array}$ & $\begin{array}{l}\text { Machinery and } \\
\text { electronics }\end{array}$ & 10 & 0.14 & -0.65 & 0.91 & 1.05 & 0.68 \\
\hline 8474 & $\begin{array}{l}\text { Machinery for working } \\
\text { minerals }\end{array}$ & $\begin{array}{l}\text { Machinery and } \\
\text { electronics }\end{array}$ & 11 & 0.82 & -0.39 & 0.76 & 0.94 & 0.64 \\
\hline 8429 & $\begin{array}{l}\text { Self-propelled bulldozers, } \\
\text { excavators and road } \\
\text { rollers }\end{array}$ & $\begin{array}{l}\text { Machinery and } \\
\text { electronics }\end{array}$ & 12 & 0.49 & -0.25 & 0.43 & 0.90 & 0.57 \\
\hline 8803 & Parts of other aircraft & $\begin{array}{l}\text { Vehicles and } \\
\text { transport } \\
\text { equipment }\end{array}$ & 13 & 0.35 & -0.81 & 0.53 & 1.00 & 0.54 \\
\hline 8545 & $\begin{array}{l}\text { Carbon articles for } \\
\text { electrical purposes }\end{array}$ & $\begin{array}{l}\text { Machinery and } \\
\text { electronics }\end{array}$ & 14 & 0.12 & -0.46 & 0.79 & 0.79 & 0.54 \\
\hline 9205 & Musical instruments, wind & Instruments & 15 & 0.69 & -1.61 & 1.11 & 1.03 & 0.52 \\
\hline 8502 & $\begin{array}{l}\text { Electric generating sets } \\
\text { and rotary converters }\end{array}$ & $\begin{array}{l}\text { Machinery and } \\
\text { electronics }\end{array}$ & 16 & 0.61 & -0.45 & 0.68 & 0.72 & 0.48 \\
\hline 7302 & $\begin{array}{l}\text { Railway construction } \\
\text { material of iron or steel }\end{array}$ & Metals & 17 & 0.03 & -0.10 & 0.53 & 0.61 & 0.45 \\
\hline 7418 & $\begin{array}{l}\text { Household articles of } \\
\text { copper }\end{array}$ & Metals & 18 & 0.11 & -0.42 & 0.56 & 0.68 & 0.44 \\
\hline 6902 & $\begin{array}{l}\text { Bricks, tiles and similar } \\
\text { refractory ceramic } \\
\text { constructional goods }\end{array}$ & Stone and glass & 19 & 0.15 & -0.43 & 0.46 & 0.62 & 0.38 \\
\hline 9023 & $\begin{array}{l}\text { Instruments designed for } \\
\text { demonstrational purposes }\end{array}$ & Instruments & 20 & 0.22 & -0.17 & 0.39 & 0.52 & 0.36 \\
\hline 2826 & Fluorides & $\begin{array}{l}\text { Chemical } \\
\text { products }\end{array}$ & 21 & 0.16 & -0.51 & 0.51 & 0.53 & 0.32 \\
\hline 4702 & $\begin{array}{l}\text { Chemical woodpulp, } \\
\text { dissolving grade }\end{array}$ & Paper goods & 22 & 0.00 & -0.43 & 0.71 & 0.41 & 0.30 \\
\hline 9704 & $\begin{array}{l}\text { Postage or revenue } \\
\text { stamps }\end{array}$ & Art & 23 & 0.00 & 0.01 & 0.32 & 0.34 & 0.27 \\
\hline 7905 & Zinc plates and foil & Metals & 24 & 0.08 & -0.44 & 0.00 & 0.60 & 0.27 \\
\hline 4809 & Carbon paper & Paper goods & 25 & 0.02 & -0.58 & 0.45 & 0.49 & 0.27 \\
\hline
\end{tabular}

Note: density refers to the inverse of distance and is calculated as distance minus 1.

Source: authors' calculations based on trade data from Growth Lab (2019). 
Table A3: Target products from Diversify \& Scale strategy, low-hanging fruits component

\begin{tabular}{|c|c|c|c|c|c|c|c|c|}
\hline $\begin{array}{l}\text { HS } \\
\text { code }\end{array}$ & Description & $\begin{array}{l}\text { Product } \\
\text { section }\end{array}$ & Rank & $\mathrm{RCA}$ & Density & $\mathrm{PCl}$ & OGI & $\begin{array}{r}\text { Weighted } \\
\text { score }\end{array}$ \\
\hline 7214 & $\begin{array}{l}\text { Other bars of iron, not } \\
\text { further worked than forged }\end{array}$ & Metals & 1 & 0.01 & 2.12 & -1.16 & -1.61 & 0.88 \\
\hline 2402 & Cigars and cigarettes & Foodstuffs & 2 & 0.01 & 1.99 & -0.91 & -1.39 & 0.88 \\
\hline 2009 & Fruit juices & Foodstuffs & 3 & 0.05 & 2.09 & -1.12 & -1.59 & 0.87 \\
\hline 1104 & Worked cereal grains & $\begin{array}{l}\text { Vegetable } \\
\text { products }\end{array}$ & 4 & 0.00 & 1.69 & -0.46 & -0.87 & 0.86 \\
\hline 4104 & $\begin{array}{l}\text { Tanned hides of bovines } \\
\text { or equines }\end{array}$ & Animal hides & 5 & 0.04 & 1.86 & -1.01 & -1.40 & 0.78 \\
\hline 1102 & Cereal flours & $\begin{array}{l}\text { Vegetable } \\
\text { products }\end{array}$ & 6 & 0.02 & 1.91 & -1.19 & -1.46 & 0.77 \\
\hline 1209 & Seeds used for sowing & $\begin{array}{l}\text { Vegetable } \\
\text { products }\end{array}$ & 7 & 0.04 & 1.72 & -0.95 & -1.15 & 0.75 \\
\hline 0805 & Citrus fruit & $\begin{array}{l}\text { Vegetable } \\
\text { products }\end{array}$ & 8 & 0.02 & 1.87 & -1.20 & -1.59 & 0.72 \\
\hline 0102 & Bovine & Live animals & 9 & 0.00 & 1.49 & -0.50 & -0.88 & 0.72 \\
\hline 0304 & Fish fillets & Live animals & 10 & 0.08 & 1.78 & -1.04 & -1.47 & 0.71 \\
\hline 1704 & Confectionery sugar & Foodstuffs & 11 & 0.00 & 1.57 & -0.61 & -1.11 & 0.70 \\
\hline 2403 & $\begin{array}{l}\text { Other manufactured } \\
\text { tobacco }\end{array}$ & Foodstuffs & 12 & 0.04 & 1.48 & -0.61 & -1.04 & 0.66 \\
\hline 2207 & Ethyl alcohol > 80\% & Foodstuffs & 13 & 0.00 & 1.67 & -1.12 & -1.27 & 0.66 \\
\hline 0407 & Eggs, in shell & Live animals & 14 & 0.00 & 1.41 & -0.52 & -1.03 & 0.63 \\
\hline 7902 & Zinc waste and scrap & Metals & 15 & 0.06 & 1.45 & -0.77 & -1.00 & 0.63 \\
\hline 3301 & Essential oils & $\begin{array}{l}\text { Chemical } \\
\text { products }\end{array}$ & 16 & 0.01 & 1.72 & -1.15 & -1.60 & 0.62 \\
\hline 0409 & Honey & Live animals & 17 & 0.00 & 1.64 & -0.93 & -1.53 & 0.62 \\
\hline 0402 & Milk, concentrated & Live animals & 18 & 0.04 & 1.37 & -0.77 & -0.90 & 0.60 \\
\hline 4819 & $\begin{array}{l}\text { Cardboard packing } \\
\text { containers }\end{array}$ & Paper goods & 19 & 0.07 & 1.30 & -0.52 & -0.84 & 0.60 \\
\hline 0604 & Other parts of plants & $\begin{array}{l}\text { Vegetable } \\
\text { products }\end{array}$ & 20 & 0.00 & 1.58 & -1.14 & -1.30 & 0.59 \\
\hline 0301 & Live fish & Live animals & 21 & 0.00 & 1.43 & -0.80 & -1.07 & 0.59 \\
\hline 7313 & Barbed wire of iron or steel & Metals & 22 & 0.00 & 1.57 & -1.03 & -1.45 & 0.58 \\
\hline 2101 & Coffee extracts & Foodstuffs & 23 & 0.00 & 1.34 & -0.67 & -0.99 & 0.57 \\
\hline 0811 & Fruits and nuts, frozen & $\begin{array}{l}\text { Vegetable } \\
\text { products }\end{array}$ & 24 & 0.00 & 1.34 & -0.53 & -1.10 & 0.57 \\
\hline 4707 & Paper waste & Paper goods & 25 & 0.05 & 1.05 & -0.21 & -0.54 & 0.54 \\
\hline
\end{tabular}

Note: density refers to the inverse of distance and is calculated as distance minus 1.

Source: authors' calculations based on trade data from Growth Lab (2019). 
Table A4: Target products from Diversify \& Scale strategy, strategic bets component

\begin{tabular}{|c|c|c|c|c|c|c|c|c|}
\hline $\begin{array}{l}\text { HS } \\
\text { code }\end{array}$ & Description & $\begin{array}{l}\text { Product } \\
\text { section }\end{array}$ & Rank & $\mathrm{RCA}$ & Density & $\mathrm{PCl}$ & OGI & $\begin{array}{r}\text { Weighted } \\
\text { score }\end{array}$ \\
\hline 6806 & $\begin{array}{l}\text { Mineral wools and } \\
\text { insulating materials }\end{array}$ & Stone and glass & 1 & 0.03 & -0.13 & 0.93 & 1.13 & 0.48 \\
\hline 1104 & Worked cereal grains & $\begin{array}{l}\text { Vegetable } \\
\text { products }\end{array}$ & 2 & 0.00 & 1.69 & -0.46 & -0.87 & 0.45 \\
\hline 9033 & $\begin{array}{l}\text { Other parts for machines } \\
\text { and appliances }\end{array}$ & Instruments & 3 & 0.00 & 0.01 & 0.95 & 0.86 & 0.44 \\
\hline 8801 & Gliders, hang gliders & $\begin{array}{l}\text { Vehicles and } \\
\text { transport } \\
\text { equipment }\end{array}$ & 4 & 0.00 & 0.47 & 0.40 & 0.41 & 0.44 \\
\hline 8428 & Other lifting machinery & $\begin{array}{l}\text { Machinery and } \\
\text { electronics }\end{array}$ & 5 & 0.09 & -0.62 & 1.23 & 1.49 & 0.41 \\
\hline 8433 & $\begin{array}{l}\text { Harvesting or agricultural } \\
\text { machinery }\end{array}$ & $\begin{array}{l}\text { Machinery and } \\
\text { electronics }\end{array}$ & 6 & 0.00 & -0.37 & 0.99 & 1.23 & 0.40 \\
\hline 8608 & Railway track fixtures & $\begin{array}{l}\text { Vehicles and } \\
\text { transport } \\
\text { equipment }\end{array}$ & 7 & 0.07 & 0.03 & 0.72 & 0.79 & 0.40 \\
\hline 4008 & Vulcanized rubber plates & $\begin{array}{l}\text { Plastics and } \\
\text { rubbers }\end{array}$ & 8 & 0.01 & -0.60 & 1.12 & 1.47 & 0.40 \\
\hline 8709 & Work trucks & $\begin{array}{l}\text { Vehicles and } \\
\text { transport } \\
\text { equipment }\end{array}$ & 9 & 0.00 & -0.26 & 0.88 & 1.10 & 0.40 \\
\hline 7307 & $\begin{array}{l}\text { Tube or pipe fittings of iron } \\
\text { or steel }\end{array}$ & Metals & 10 & 0.01 & -0.72 & 1.21 & 1.60 & 0.40 \\
\hline 8436 & $\begin{array}{l}\text { Other agricultural } \\
\text { machinery }\end{array}$ & $\begin{array}{l}\text { Machinery and } \\
\text { electronics }\end{array}$ & 11 & 0.00 & -0.45 & 1.12 & 1.28 & 0.40 \\
\hline 8432 & $\begin{array}{l}\text { Machinery for soil } \\
\text { preparation or cultivation }\end{array}$ & $\begin{array}{l}\text { Machinery and } \\
\text { electronics }\end{array}$ & 12 & 0.05 & 0.09 & 0.66 & 0.71 & 0.40 \\
\hline 5911 & $\begin{array}{l}\text { Textile articles for } \\
\text { technical use }\end{array}$ & Textiles & 13 & 0.00 & -0.67 & 1.30 & 1.49 & 0.39 \\
\hline 3921 & $\begin{array}{l}\text { Other plastic plates, } \\
\text { sheets etc. }\end{array}$ & $\begin{array}{l}\text { Plastics and } \\
\text { rubbers }\end{array}$ & 14 & 0.00 & 0.11 & 0.70 & 0.66 & 0.39 \\
\hline 8442 & $\begin{array}{l}\text { Machinery for making } \\
\text { printing components }\end{array}$ & $\begin{array}{l}\text { Machinery and } \\
\text { electronics }\end{array}$ & 15 & 0.00 & -0.67 & 1.23 & 1.48 & 0.38 \\
\hline 4911 & Other printed matter & Paper goods & 16 & 0.04 & 0.09 & 0.71 & 0.63 & 0.37 \\
\hline 7211 & $\begin{array}{l}\text { Flat-rolled iron, width } \\
<600 \mathrm{~mm} \text {, not clad }\end{array}$ & Metals & 17 & 0.00 & -0.19 & 0.76 & 0.97 & 0.37 \\
\hline 4902 & $\begin{array}{l}\text { Newspapers, journals and } \\
\text { periodicals }\end{array}$ & Paper goods & 18 & 0.02 & -0.33 & 0.92 & 1.10 & 0.37 \\
\hline 8524 & $\begin{array}{l}\text { Tapes, cassettes, records } \\
\text { and compact disks }\end{array}$ & $\begin{array}{l}\text { Machinery and } \\
\text { electronics }\end{array}$ & 19 & 0.02 & -0.23 & 0.99 & 0.96 & 0.37 \\
\hline 7326 & $\begin{array}{l}\text { Other articles of iron or } \\
\text { steel }\end{array}$ & Metals & 20 & 0.02 & -0.40 & 0.98 & 1.16 & 0.36 \\
\hline 2402 & Cigars and cigarettes & Foodstuffs & 21 & 0.01 & 1.99 & -0.91 & -1.39 & 0.35 \\
\hline 8468 & Machinery for soldering & $\begin{array}{l}\text { Machinery and } \\
\text { electronics }\end{array}$ & 22 & 0.08 & -0.54 & 0.95 & 1.31 & 0.35 \\
\hline 8546 & $\begin{array}{l}\text { Electrical insulators of any } \\
\text { material }\end{array}$ & $\begin{array}{l}\text { Machinery and } \\
\text { electronics }\end{array}$ & 23 & 0.00 & -0.37 & 0.92 & 1.10 & 0.34 \\
\hline 0102 & Bovine & Live animals & 24 & 0.00 & 1.49 & -0.50 & -0.88 & 0.34 \\
\hline 2106 & Food preparations n.e.c. & Foodstuffs & 25 & 0.01 & 0.73 & 0.23 & -0.14 & 0.33 \\
\hline
\end{tabular}

Note: density refers to the inverse of distance and is calculated as distance minus 1 .

Source: authors' calculations based on trade data from Growth Lab (2019). 
Figure A1: Total PEP and average PEP by product section and strategy (OLS)
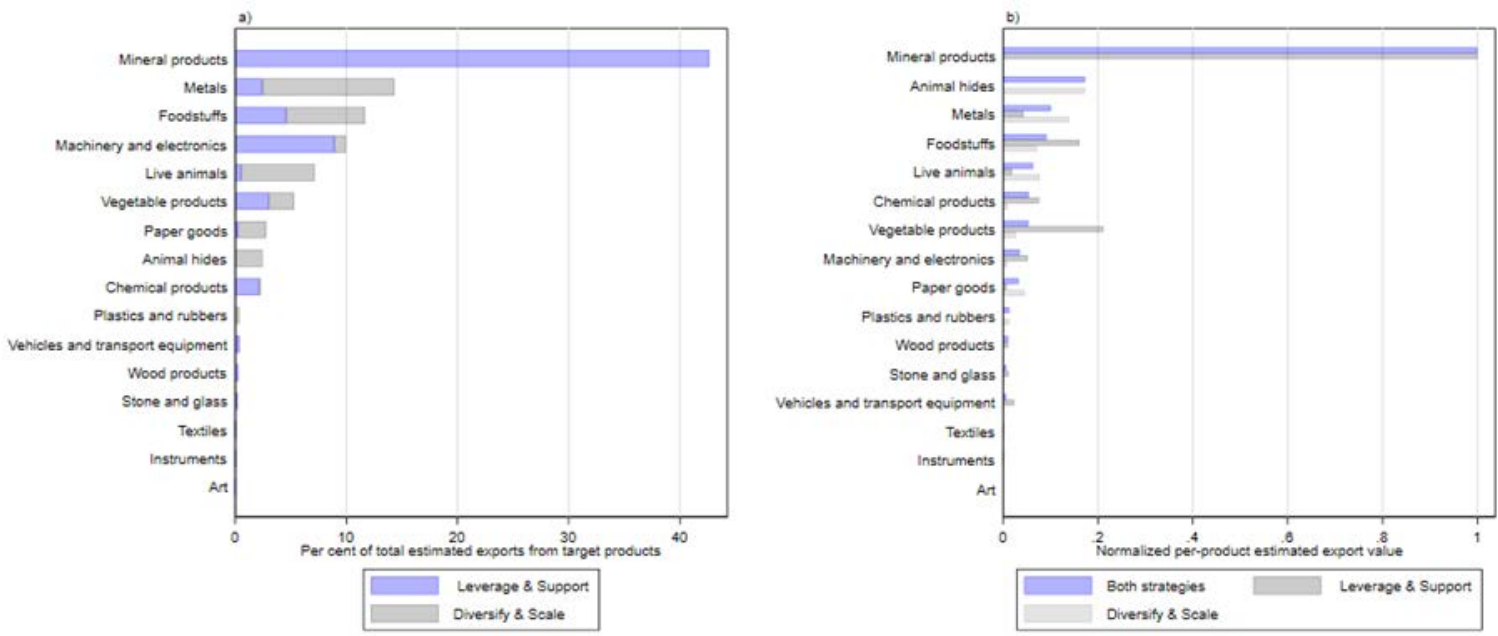

Note: PEP estimates are based on the OLS regression without fixed effects (Column 1, Table 4).

Source: authors' calculations based on trade data from Growth Lab (2019).

Figure A2: Total PEP and average PEP by product section and strategy (OLS fixed effects)
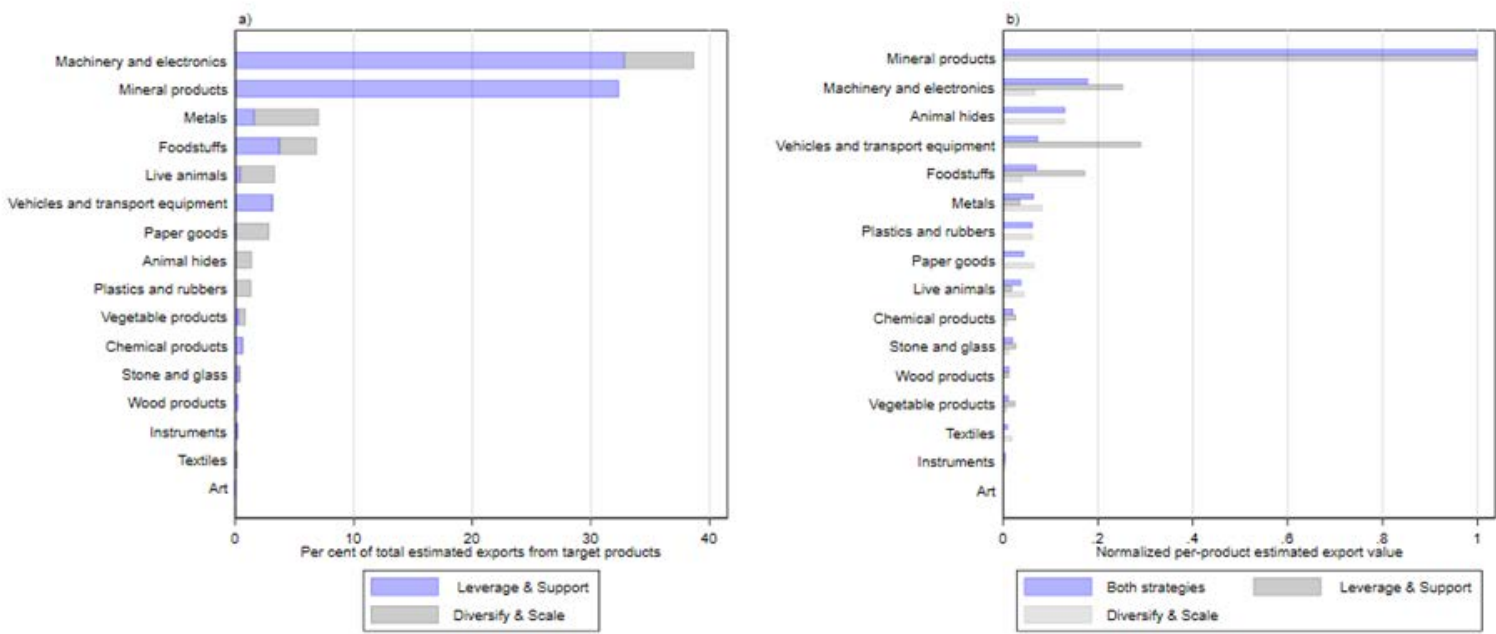

Note: PEP estimates are based on the OLS regression with exporter-year and importer-year fixed effects (Column 2, Table 4).

Source: authors' calculations based on trade data from Growth Lab (2019). 
Figure A3: Total PEP and average PEP by product section and strategy (PPML)
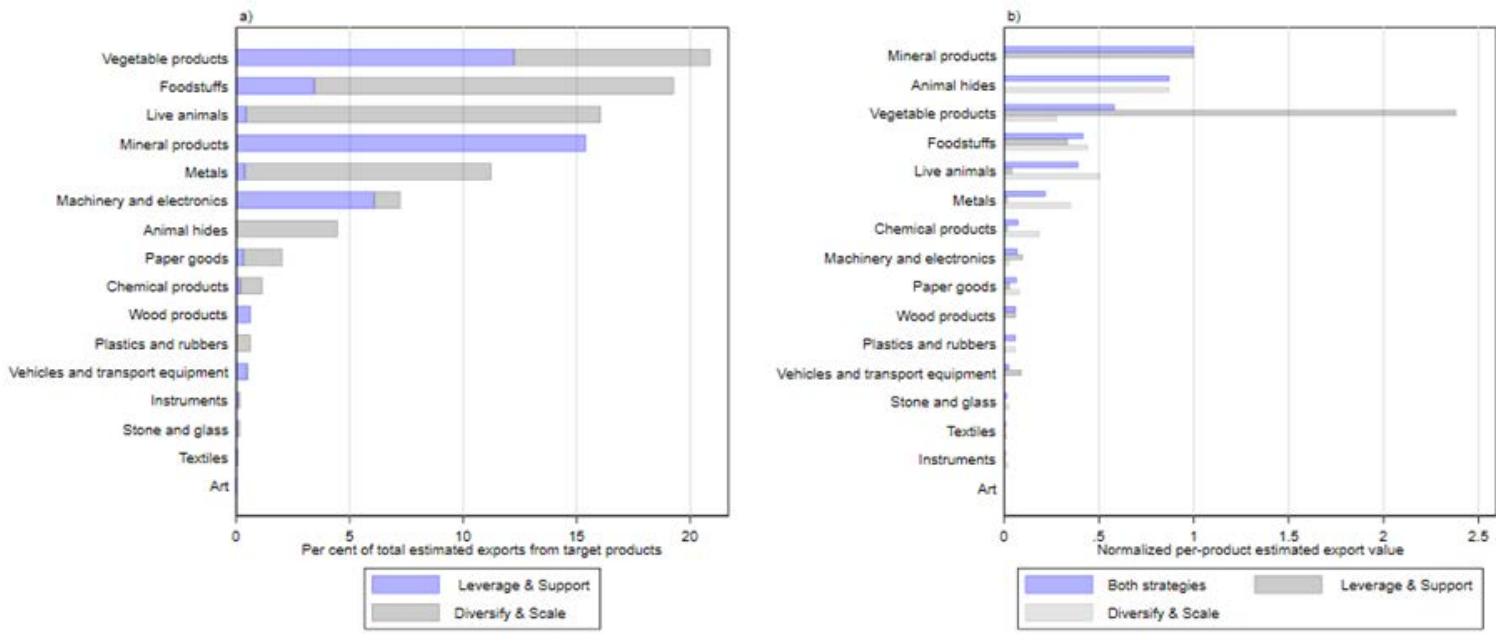

Note: PEP estimates are based on the PPML regression without fixed effects (Column 3, Table 4).

Source: authors' calculations based on trade data from Growth Lab (2019). 
Figure A4: Import share of Mozambique's 2018 exports versus import share of Mozambique's estimated target product exports over eight years (OLS)

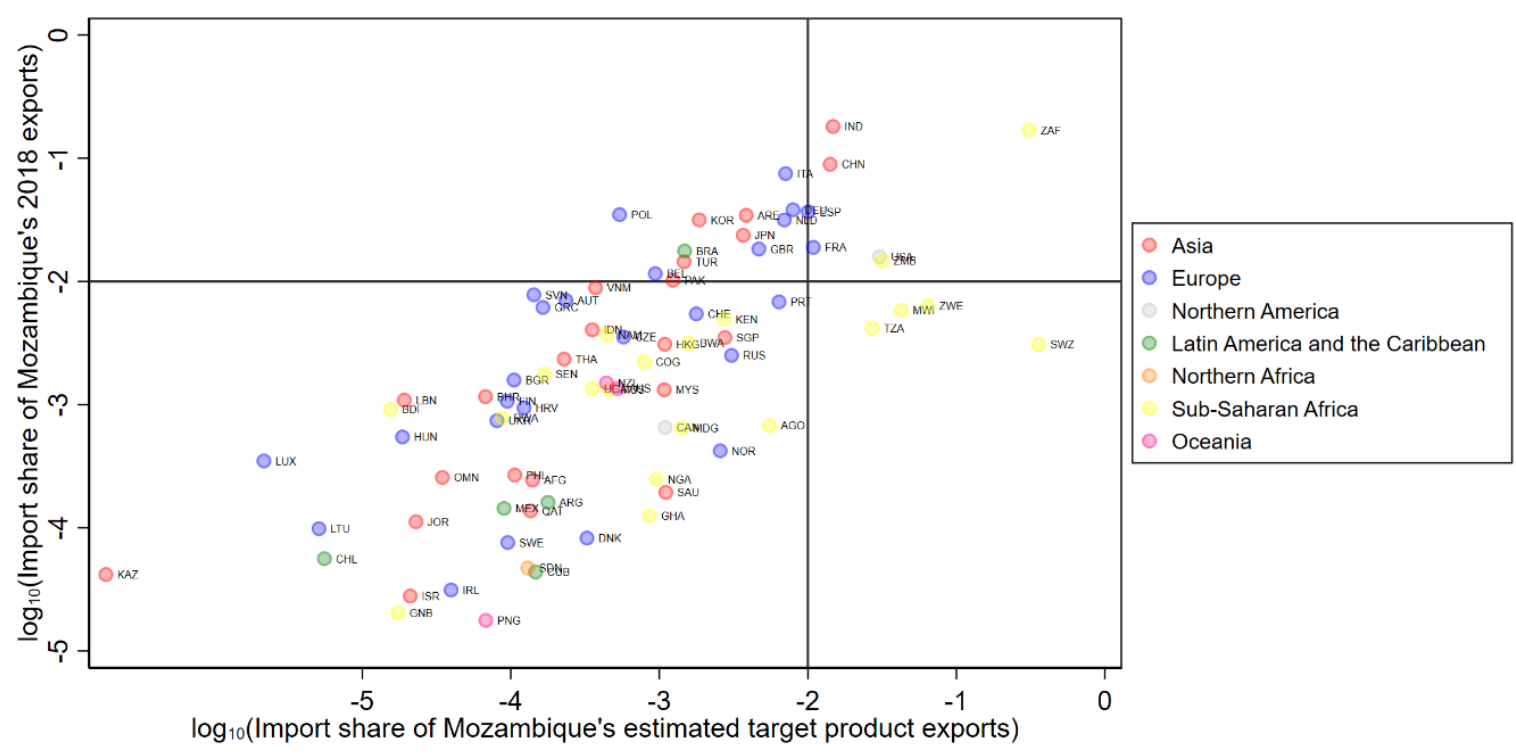

Note: MEP estimates are based on the OLS regression without fixed effects (Column 1, Table 4).

Source: authors' calculations based on trade data from Growth Lab (2019).

Figure A5: Import share of Mozambique's 2018 exports versus import share of Mozambique's estimated target product exports over eight years (OLS fixed effects)

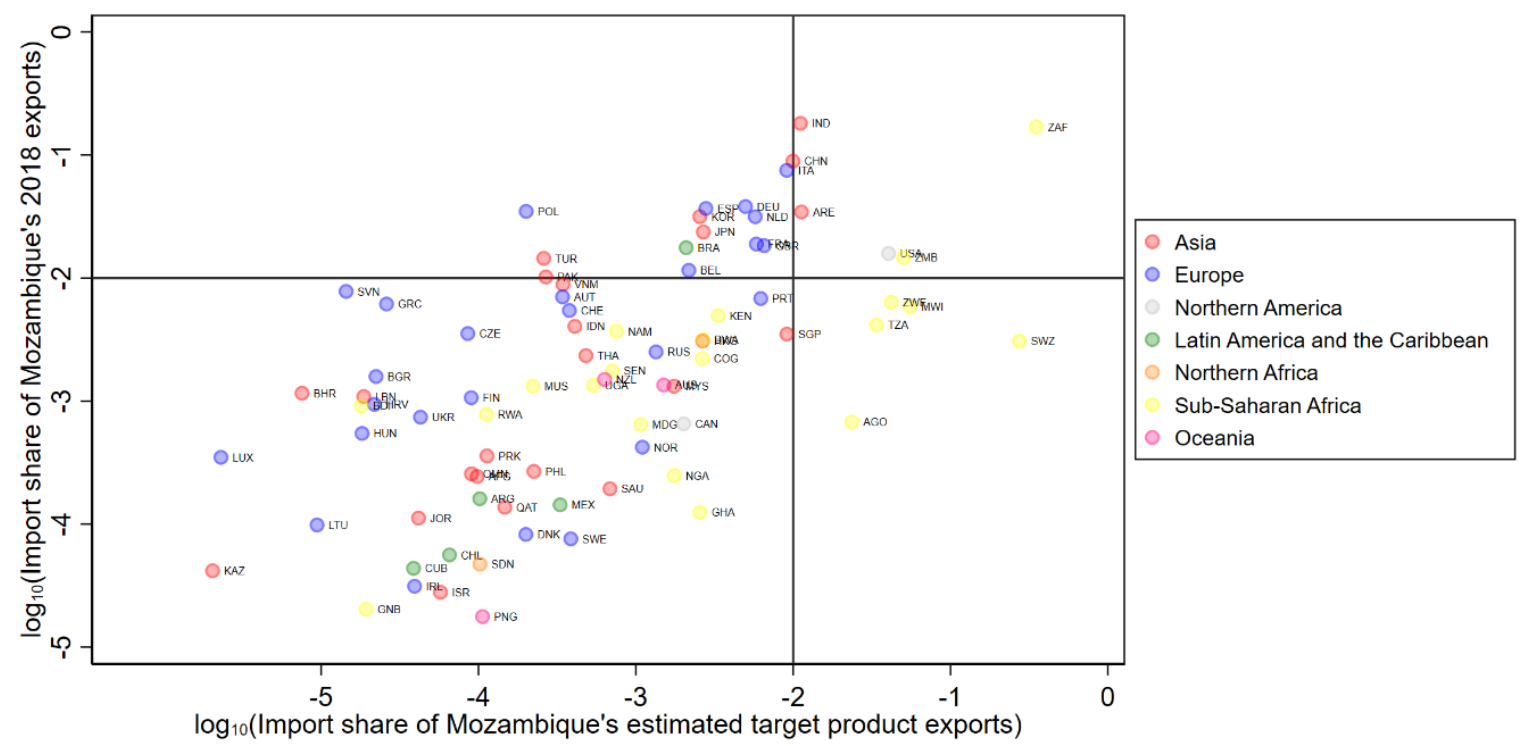

Note: MEP estimates are based on the OLS regression with exporter-year and importer-year fixed effects (Column 2, Table 4).

Source: authors' calculations based on trade data from Growth Lab (2019). 
Figure A6: Import share of Mozambique's 2018 exports versus import share of Mozambique's estimated target product exports over eight years (PPML)

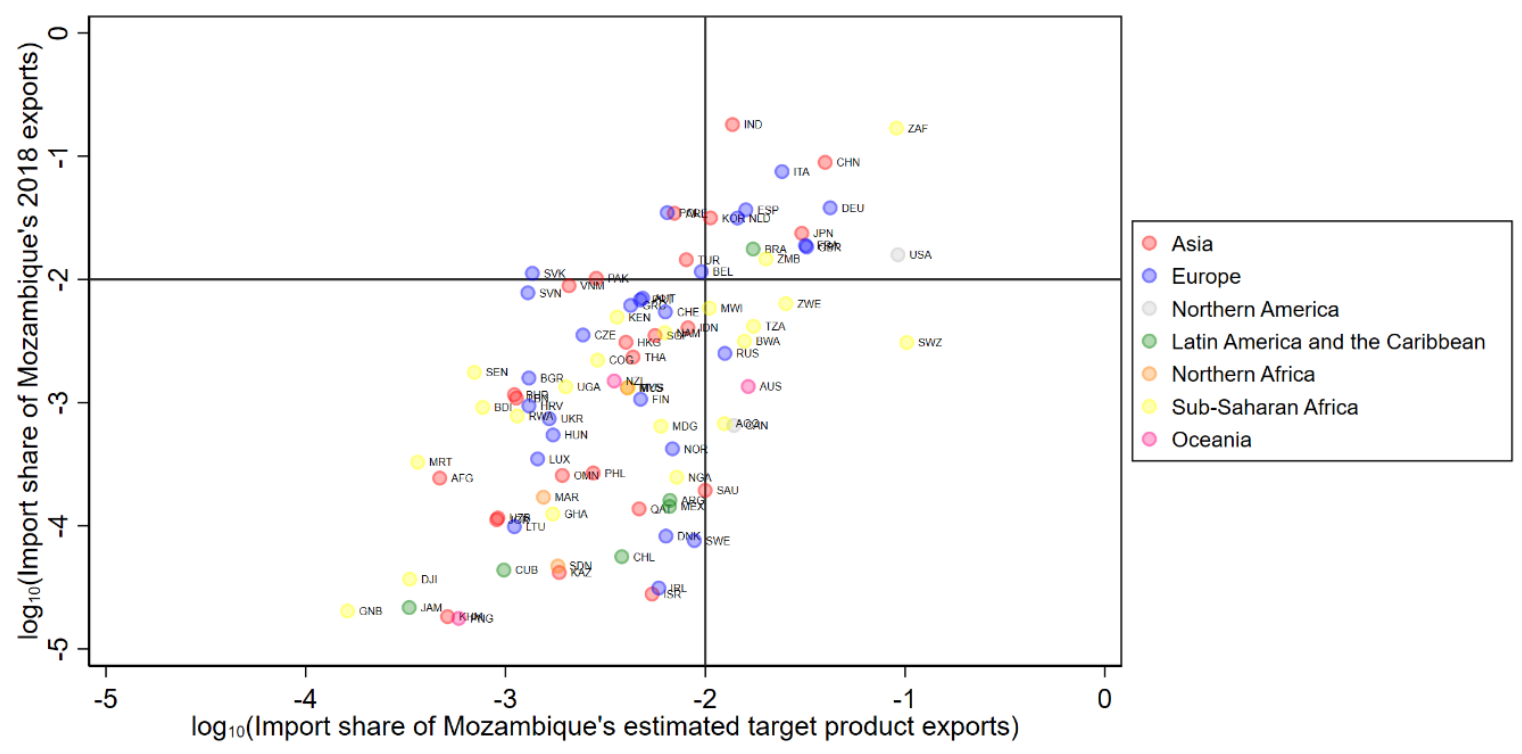

Note: MEP estimates are based on the PPML regression without fixed effects (Column 3, Table 4).

Source: authors' calculations based on trade data from Growth Lab (2019). 